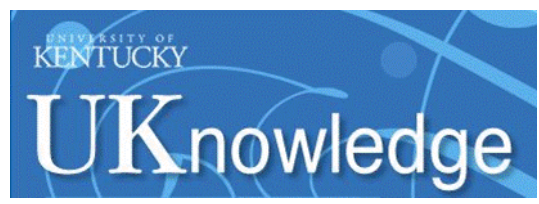

University of Kentucky

UKnowledge

$10-26-2017$

\title{
Single Versus Concurrent Systems: Nominal Classification in Mian
}

Greville G. Corbett

University of Surrey, UK

Sebastian Fedden

Université Sorbonne Nouvelle, France

Raphael Finkel

University of Kentucky, raphael.finkel@uky.edu

Follow this and additional works at: https://uknowledge.uky.edu/cs_facpub

Part of the Computer Sciences Commons, and the Typological Linguistics and Linguistic Diversity

Commons

Right click to open a feedback form in a new tab to let us know how this document benefits you.

\section{Repository Citation}

Corbett, Greville G.; Fedden, Sebastian; and Finkel, Raphael, "Single Versus Concurrent Systems: Nominal Classification in Mian" (2017). Computer Science Faculty Publications. 14.

https://uknowledge.uky.edu/cs_facpub/14

This Article is brought to you for free and open access by the Computer Science at UKnowledge. It has been accepted for inclusion in Computer Science Faculty Publications by an authorized administrator of UKnowledge. For more information, please contact UKnowledge@lsv.uky.edu. 


\section{Single Versus Concurrent Systems: Nominal Classification in Mian}

Digital Object Identifier (DOI)

https://doi.org/10.1515/lingty-2017-0006

\section{Notes/Citation Information}

Published in Linguistic Typology, v. 21, issue 2, p. 209-260.

(c) 2017 Walter de Gruyter GmbH, Berlin/Boston.

The copyright holder has granted the permission for posting the article here. 


\section{Greville G. Corbett, Sebastian Fedden* and Raphael Finkel Single versus concurrent systems: Nominal classification in Mian}

https://doi.org/10.1515/lingty-2017-0006

Received June 23, 2016; revised November 16, 2016

Abstract: The Papuan language Mian allows us to refine the typology of nominal classification. Mian has two candidate classification systems, differing completely in their formal realization but overlapping considerably in their semantics. To determine whether to analyse Mian as a single system or concurrent systems we adopt a canonical approach. Our criteria - orthogonality of the systems (we give a precise measure), semantic compositionality, morphosyntactic alignment, distribution across parts of speech, exponence, and interaction with other features - point mainly to an analysis as concurrent systems. We thus improve our analysis of Mian and make progress with the typology of nominal classification.

Keywords: agreement, Canonical Typology, classifiers, gender, inflection, inflectional categories, Mian, morphology, number

\section{Introduction}

The Papuan language Mian is proving a key to refining the typology of nominal classification. To get a sense of the challenge, consider first the example in (1). The essential elements are in bold and, to encourage the reader to keep an open mind, we omit their glosses for now:

(1) unáng=o naka=e dob-ò'-s-o=be

woman=? man=? ?-take-RPST-?=DECL

'The woman married the man.'

*Corresponding author: Sebastian Fedden, Institut de Linguistique et Phonétique Générales et Appliquées, Université Sorbonne Nouvelle - Paris 3, 19 Rue des Bernardins, 75005 Paris, France, E-mail: sebastian.fedden@gmail.com

Greville G. Corbett, Surrey Morphology Group, Literature and Languages (11), Faculty of Arts and Social Sciences, University of Surrey, Guildford, Surrey, GU2 7XH, United Kingdom, E-mail: g.corbett@surrey.ac.uk

Raphael Finkel, Computer Science Department, University of Kentucky, 230 Hardymon Building, Lexington, KY 40506-0495, U.S.A., E-mail: raphael@cs.uky.edu 
Look first at the $-o$, within the verb. This marks subject agreement, and it forms part of a four-way opposition, based on grammatical meanings such as 'masculine' and 'feminine'. Compare the clitic article $=o$ on the first noun unáng 'woman', which marks the same value. The article $=e$ on the second noun naka 'man' is part of the same set of oppositions. Now look at the prefixal dob- on the verb. This is associated with the direct object (naka 'man'). It is part of a six-way opposition, based on distinctions such as 'long' and 'bundle-like', but also including 'male' and 'female'. How many systems are involved here? There are different markers and different numbers of oppositions. And yet, given a particular noun associated with the $d o b$ - marker we would predict that its article would be $=e$, but we could not do so with complete reliability. To add to the difficulty, the discussion so far has hinted at gender-like properties and classifier-like properties. We shall give further detail to fill out the picture, and we ask the reader to suspend judgement while we do so below.

It is not easy to determine whether we have a single system here or more than one. Indeed, the study of Mian was the initial stimulus that led eventually to a typology of single versus concurrent systems (Fedden \& Corbett 2017), and yet ironically Mian seems to escape from the typology built around it. In particular, as we shall see, we devised a measure to help in such cases, and the score for Mian was somewhat inconclusive. We therefore apply additional tests for concurrent systems, which were originally devised for the analysis of concurrent systems in Kayardild (Tangkic, northern Australia; Round \& Corbett (2016)). This article goes substantially beyond these previous papers. Mian is discussed in much more detail here than in Fedden \& Corbett (2017) and we use the interaction of the candidate systems with a third feature (number) as a new criterion in the analysis of Mian. In the present article we also develop a new "two systems computation tool", which allows us to calculate how close any set of candidate systems comes to canonically concurrent systems. Furthermore, the criteria from Round \& Corbett (2016) were developed for the analysis of Kayardild tense-aspect-mood as single or concurrent systems. Their application to nominal classification is new.

There are three results from this research: we obtain a clearer perspective on the specific interest of Mian; we refine the typology of nominal classification; and we make progress on the larger issue of the analysis of single versus concurrent systems.

The article is structured as follows. In Section 2 we provide essential information on Mian and its two candidate systems of nominal classification. Section 3 gives a succinct summary of our typology of single and concurrent systems. Details on gender and classifiers in Mian are presented in Section 4, as essential preparation for the discussion of whether Mian really has concurrent systems or 
whether this language is better analysed as having a single system. In Section 5 we take a step back from Mian and consider the bigger picture, examining the motivation for the use of features in linguistic analysis. In Section 6 we discuss orthogonality of features, i.e., the degree to which the candidate systems cross-cut each other. In Sections 7 to 10 we adduce further criteria which help in resolving the question of single versus concurrent systems for Mian (semantic compositionality, syntax, distribution across parts of speech, exponence, respectively). Section 11 goes into detail on the surprising interaction with another feature in the grammar of Mian, namely number. In Section 12 we put the Mian gender and classifier systems into a typological context. ${ }^{1}$ Finally, in Section 13 we offer our conclusions.

\section{The essentials}

To get started, we need basic information on Mian (Section 2.1), and in particular on its means of nominal classification (Section 2.2). It has been suggested previously that Mian has concurrent systems of nominal classification (Fedden 2011: 195-196), and we therefore discuss a typology which includes this possibility (Section 2.3); we do so using a canonical approach (Section 2.4).

\subsection{Mian}

Mian belongs to the Ok family of languages, named after the word ok 'river, water' (Healey 1964). The Ok family is part of the large Trans New Guinea family (Wurm 1982; Ross 2005; Pawley 2005). Mian is spoken in the Telefomin District of Sandaun Province in Papua New Guinea. The eastern dialect, which has approximately 1,400 speakers, is described in Fedden's comprehensive grammar (Fedden 2011). The members of the community are native speakers of Mian. Most speakers under 75 also speak Tok Pisin, the variety of Neo-Melanesian Pidgin spoken in Papua New Guinea. Most young speakers have some knowledge of English. Male speakers over 50 also speak the neighbouring language Telefol, which is closely related to Mian.

1 We use "system" as a general term, while "feature" is more restricted, being limited to inflectional categories such as gender, number, case, and person. Thus features are systems, while a system of classifiers might or might not be modelled using a feature. 
Mian is a word tone language, that is, its five lexically specified tonal melodies contrast within the entire phonological word rather than the syllable (Donohue 1997). In our examples, the tonal melodies are written as follows: mèn 'child' (H), mén ‘string bag' (LH), klâ 'properly' (LHL), fè ‘carrion' (HL). Low tone is not indicated, thus am 'house' (L). Mian is head-marking. Its syntax is characterized by frequent use of serial verb constructions and clause chaining. The neutral constituent order is SOV. The language is strongly zero-anaphoric: all argument noun phrases are typically elided if referent identity is retrievable from context or world knowledge.

\section{2 "Gender" and "classifiers" in Mian}

Mian is of special interest because it arguably has two systems of nominal classification. The first one is a GENDER system with four values: MASCULINE, FEMININE, NEUTER 1, and NEUTER 2 (glossed M, F, N1, N2). Targets are articles, verbs, and pronouns. The second system is called a system of verbal classifiers in Fedden (2011); CLASSIFIER has the values M-CLASSIFIER (glossed M_CL), F-CLASSIFIER (glossed F_CL), LONG, BUNDLE, COVERING, and RESIDUE. The terms "M-CLASSIFIER" and "F-CLASSIFIER" distinguish the relevant classifiers from the MASCULINE and FEMININE gender values. While there is some overlap between the MASCULINE gender and the M-CLASSIFIER on the one hand and between the FEMININE gender and the F-CLASSIFIER on the other, gender values and classifiers are not coextensive. As we shall see, besides properties we might expect in a verbal classifier system, this system also has properties often associated with gender systems. For more on verbal classification, see Passer (2016) and references there. We can now fully gloss our example, as in (2), repeated from (1).

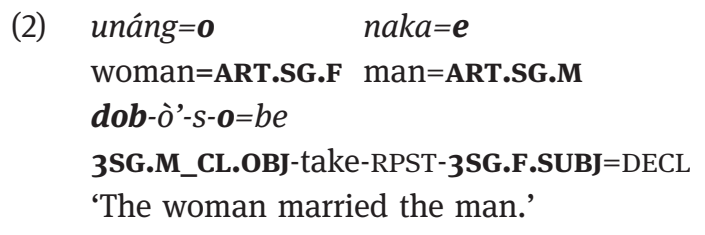

In Mian, 37 verbs take a classifier. In addition, there are seven verbs which agree with their object. The remaining transitive verbs neither take a classifier nor agree with their object. There is no overlap between the verbs that take a classifier and the verbs that agree with their object. An example of a verb that agrees with its object is given in (3). 


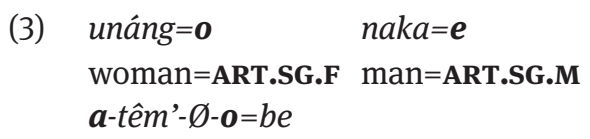

3SG.M.OBJ-See.PFV-REAL-3SG.F.SBJ=DECL

'The woman saw the man.'

Note the difference between the classifier dob- in (2) and the object agreement marker $a$ - in (3). We need distinct labels to refer to these candidate systems, while discussing whether Mian is better analysed as having two systems or one; we follow Fedden (2011) and retain temporarily the terms "gender" and "classifier". We shall say that nouns "control" agreement in a particular gender value (directly or through a larger constituent), and that nouns are "associated with" a particular classifier (again, directly or indirectly). From the perspective of the lexicon, we say that gender values and classifiers are "assigned" to nouns (we return to the degree to which these assignments are semantically motivated in Sections 4.1 and 4.2). ${ }^{2}$

\subsection{Single versus concurrent systems (wider considerations)}

The specific question whether a language has one system of nominal classification or two is part of the general issue of distinguishing single systems from concurrent systems. This topic is significant and difficult; moreover, the answer to the question is often taken for granted, rather than being supported by convincing arguments. There are some exceptions to this trend, for instance, Goddard (1982) on case in Australian languages, Corbett (2012: 224-233) on gender and number as concurrent systems in Cushitic, Round \& Corbett (2016) on tense-aspect-mood in Kayardild, and Fedden \& Corbett (2017) on single and concurrent systems of nominal classification.

When discussing nominal classification systems, scholars have sometimes put overdue emphasis on differences in the formal realization of a value. For example, minor formal differences in classifiers appearing on numerals and articles would prompt some analysts to posit numeral classifiers and deictic classifiers as

2 Thornton (2009: 14-15) points out that assignment can be viewed in two ways: we may talk of assigning gender values to nouns (focussing on the function of the feature in the syntax); but we also talk of assigning nouns to genders (where gender values are conceptualized as containers, focussing on cognitive classification). We shall take the first perspective, and talk of "assigning” gender values (and classifiers) to nouns. 
concurrent systems of nominal classification in a language. Without further argumentation this move is problematic. In the analysis of gender systems it is a common occurrence that agreements on certain targets differ in their formal realization, but these agreements are still part of a set of agreement markers defining a gender value. For example, in French, feminine gender in the singular is realized differently on the article, $l a$, and the adjective (final consonant depending on the adjective, e.g., contente /kõtã-t/ [happy-F.SG]). Nonetheless, these different formal realizations are mutually predictable because they are phonologically distinct realizations of the same value, in this example FEMININE. No one would take the situation in French as a cue to say that the language has concurrent systems of adjective gender and article gender. In order to make progress, to analyse systems in consistent terms, we adopt a canonical approach.

\subsection{Canonical Typology}

There is a tradition of work on the typology of nominal classification, e.g., Aikhenvald (2000), Grinevald (2000), and Kilarski (2013). Yet there are still severe problems. The earlier view, maintaining an opposition between gender and classifiers, is no longer tenable. Languages like Mian have helped lead to this conclusion. Mian, arguably, has both a gender system and a classifier system. And yet the two systems (if there are two) are not clearly different, as we shall see. In general, there are continuing difficulties of definition (Seifart 2010: 719-721). Corbett \& Fedden (2016) suggest that we can make progress by adopting a canonical approach. To do this we establish the properties of a "canonical" or ideal system, and then take these properties as the baseline for calibrating actual examples. This approach means we are not forced to decide whether a given system is a gender or a classifier system; rather we can simply measure where an actual system is located in the typological space (as defined by the canonical ideal).

The key ideas of Canonical Typology have been laid out in various places. Brown \& Chumakina (2013) offer an outline, followed by a varied set of applications of the approach by different researchers, mainly in the areas of morphology and syntax. More recently, Bond (forthcoming) provides a helpful overview. ${ }^{3}$

3 Work within this approach that is particularly relevant to gender and classifiers includes: Corbett (2006, 2012, 2013), Polinsky (2003), Seifart (2005:156-74), Audring (forthcoming). At http://www.smg.surrey.ac.uk/approaches/canonical-typology/bibliography/ a working bibliography of research in Canonical Typology can be found. 


\section{Typology of single and concurrent systems of nominal classification}

In Fedden \& Corbett (2017) we present a typology of single and concurrent systems of nominal classification. The essential ideas behind this typology are: (i) the degree to which the SEMANTICS of the two (candidate) systems are orthogonal to each other, i.e., the extent to which their sets of grammatical meanings cross-cut each other, ${ }^{4}$ and

(ii) the degree to which their MEANS OF REALIZATION are different.

We divide each of these dimensions into three possibilities. The sets of grammatical meanings can be the same, they can be different, or the sets can partially overlap. Likewise the sets of forms which realize the grammatical meanings can be the same, different, or show partial overlap. This yields a typology with nine types (see Table 1).

Table 1: Typology of single and concurrent systems (from Fedden \& Corbett 2017).

\begin{tabular}{llll}
\hline Form & \multicolumn{2}{l}{ Semantics (grammatical meaning) } \\
\cline { 2 - 4 } & Same & Partial overlap & Different \\
\hline Same & A1 & B1 & C1 \\
Partial overlap & A2 & B2 & C2 \\
Different & A3 & B3 & C3 \\
\hline
\end{tabular}

In order to illustrate the ideas behind the typology in Table 1 we highlight the canonical Types A1 (same semantics and same sets of forms, i.e., canonically a single system) and C3 (different semantics and different sets of forms, canonically concurrent systems). For full details about each individual type we refer the reader to Fedden \& Corbett (2017).

Lamnso (Grassfields branch of Southern Bantoid) approaches our canonical Type A1. Lamnso has six gender values, and for most targets, the sets of

4 For semantics we are concerned with GRAMMATICAL meaning. Given a language which distinguishes human vs. nonhuman, masculine vs. feminine, long vs. short, or similar, we ask whether (i) the systems are fully orthogonal, i.e., whether all combinations are found; and (ii) whether different targets make the same distinctions. Thus it does not matter whether the assignment of these specifications is based purely on semantic grounds or by a combination of semantic and formal criteria. 
agreements are identical; see, e.g., the demonstratives in (4) and numerals in (5) from McGarrity \& Botne (2001: 57-58). (There are some targets for which the agreements are slightly different.)

(4) Lamnso
a. ki-soo ki-sa
SG-hoe(IV) IV.SG-that
'that hoe'
b. vi-soo vi-sa
PL-hoe(IV) IV.PL-that
'those hoes'

(5) Lamnso
a. ki-tam
ki-mo?on
sG-elephant(IV) IV.sG-one
'one elephant'
b. vi-tam vi-taar
PL-elephant(IV) IV.PL-three
'three elephants'

We would not say that Lamnso has "demonstrative gender" and "numeral gender”, rather that it has one gender system, realized on different targets.

As an example of our canonical Type C3, i.e., a language with concurrent systems, we choose Paumarí, an Arawan language from Brazil (Chapman \& Derbyshire 1991; Aikhenvald 2010). Paumarí has two gender systems: there are two different systems of grammatical meaning, with distinct means of expression. The first one is a MASCULINE vs. FEMININE system. The values of the second system are called $K A$-CLASS and NON-KA-CLASS in the literature, because the assignments are rather complex and the values are expressed by the presence or absence of an agreement prefix ka-. What is important about Paumarí is that all four combinations of values are attested; we give an instance of each of the four types of noun in Table 2 .

Table 2: Evidence for concurrent systems in Paumarí.

\begin{tabular}{lll}
\hline & KA-CLASS & NON-KA-CLASS \\
\hline MASCULINE & vahajari 'alligator' & jomahi 'jaguar' \\
FEMININE & ojoro 'turtle' & arabo 'land, ground' \\
\hline
\end{tabular}


The two Paumari systems are fully orthogonal, and the sets of forms used in these systems are fully distinct (for examples, see the sources cited above, and Aikhenvald (2000: 72-73)). This language is therefore of Type C3.

An important question is how we determine whether a certain cell in the typology exemplifies a single system or concurrent systems. If there is a unified semantics (one system of grammatical meanings, as in Footnote 4 above) we assume a single system (Types A1 to A3 in Table 1). Conversely, if the semantics of the candidate systems are different, the language has concurrent systems (Types C1 to C3 in Table 1). The difficult cases are those in which the semantics of the candidate systems overlap. Here the forms are crucial. If they are the same, the language has a single system (Type B1), if they differ, the systems are concurrent (Type B3). At the centre of our typology is Type B2, where both the semantics and the forms show partial overlap. In such cases we cannot determine the number of systems based just on semantics and forms; we have to adduce further evidence from other areas of the language. As we shall see, further tests are valuable when the basic evidence is not clear-cut.

\section{Nominal classification in Mian}

Let us return to the two candidate systems of Mian. In this section we give the essential points about the gender system and the classifier system. More detail on both can be found in Fedden (2011); for discussion of the place of Mian as a Type B3 language in the typology presented briefly in Section 3, see Fedden \& Corbett (2017).

\section{1 "Gender"}

Gender in Mian is realized on articles (e.g., unáng=o [woman=ART.SG.F] 'the woman') and other determiners within the noun phrase, such as adnominal demonstratives (e.g., naka èle [man DEM.SG.M] 'this man'). Outside the noun phrase, the agreement target is the verb. Example (6) illustrates agreement of the article and subject- and object-agreement on the verb.

$\begin{array}{ll}\text { (6) } \bar{e} \quad \text { unáng=o } & \text { wa-têm'- } \emptyset \text {-e=be } \\ \text { 3SG.M woman=ART.SG.F } & \text { 3SG.F.OBJ-See.PFV-REAL-3SG.M.SBJ=DECL } \\ \text { 'He saw the woman.' } & \end{array}$

Overt argument noun phrases are always optional, as is typical of Papuan languages (Foley 2000: 357). All agreement targets show exactly the same 
agreement pattern; in (7) we present the forms of the article. ${ }^{5}$ (Tables for all other agreement targets are found at the end of this section.)
a. naka=e 'a/the man'
$n a k a=i \quad$ '(the) men'
b. unáng=o 'a/the woman'
unáng=i '(the) women'
c. tóm $=e \quad$ 'a/the stone'
tóm $=0$ '(the) stones'
d. $a m=o \quad$ 'a/the house'
$a m=0 \quad$ '(the) houses'

We can distinguish four formally distinct controller genders in Mian. Controller genders are established on the basis of distinct agreements. For many languages controller genders have to be distinguished from target genders, i.e., the number of genders that are marked on the agreement targets (Corbett 1991: 151). Mian is such a language. This issue is discussed in more detail in Section 10. The controller genders in Mian are given in (8):
a. MASCULINE $(=e,=i)$, e.g., naka 'man'
b. FEMININE $(=0,=i)$, e.g., unáng 'woman'
c. NEUTER $1(=e,=0)$, e.g., tóm 'stone'
d. NEUTER $2(=0,=0)$, e.g., am 'house'6

As can be seen, there are just two distinctions on targets (two target genders) in each number.

We now turn to gender assignment, which is predominantly semantic in Mian. Nouns with human referents are either MASCULINE or FEMININE; so are nouns referring to large domestic animals (pigs, dogs) or animals with salient sexual dimorphism, like many birds of paradise. For all other animals there is a conventionalized gender, either MASCULINE or FEMININE.

5 If a noun is used referentially, it is followed by an enclitic article. These are articles rather than overt markers of NUMBER and GENDER, which a noun either invariably has or lacks. Articles are omitted when a noun is used non-referentially, e.g., as the first element in nounnoun compounds, e.g., míl-blong [bean-pod] 'bean pod', or under negation, e.g., imen blim [taro not.exist] 'there's no taro', $y \bar{a} i=b a=b e$ 'it's not a wound'.

6 Not inflecting for number is normal for Mian nouns (apart from a few exceptions) (Fedden 2011: 86). The agreement forms for NEUTER 2 are $(=0,=0)$ for count nouns like am 'house' and káawa 'steel axe', all of which have a singular and a plural, which is not reflected in the noun, the article, or the pronominal affixes on the verb. It is however possible for these nouns to make a number distinction using a numeral or distinct classifiers. This topic will be taken up in more detail in Section 11. For non-count NEUTER 2 nouns the agreement forms are just $(=0)$, examples being abstract nouns like fotom 'shame', weather phenomena like sók 'rain', or illnesses like kweim 'fever'. For these, there is no way of encoding a number distinction at all. They cannot be counted with a numeral and they do not occur with verbs which take classifiers. 
Inanimate nouns are assigned NEUTER 1, unless they belong to one of the following classes, which are NEUTER 2, namely some tools and weapons, masses, places and types of terrain, traditional body decoration, weather phenomena, illnesses, and abstract notions. Each of the neuter genders contains hundreds of nouns. We will discuss the precise number of nouns in each gender in Section 6 . We give reasons why we do not treat NEUTER 2 nouns as pluralia tantum NEUTER nouns in Section 11.2. Gender assignment is summarized in Table 3. For a detailed treatment of gender assignment see Fedden (2011: 171-178).

Table 3: Gender assignment (adapted from Fedden 2011: 172).

\begin{tabular}{|c|c|c|c|c|}
\hline \multicolumn{3}{|c|}{ Assignment criteria } & \multirow{2}{*}{$\begin{array}{l}\text { Example } \\
\text { naka 'man' } \\
\text { bimal eit 'male } \\
\text { lesser bird of } \\
\text { paradise' }\end{array}$} & \multirow{2}{*}{\begin{tabular}{l|} 
GENDER \\
MASCULINE
\end{tabular}} \\
\hline animate & $\begin{array}{l}\text { human, animal (where sex } \\
\text { readily discernible or } \\
\text { relevant) }\end{array}$ & male sex & & \\
\hline & & female sex & $\begin{array}{l}\text { unáng 'woman' } \\
\text { bimal go 'female } \\
\text { lesser bird of } \\
\text { paradise' }\end{array}$ & FEMININE \\
\hline \multirow[t]{9}{*}{ inanimate } & \multirow[t]{2}{*}{ most inanimates } & count nouns & $\begin{array}{l}\text { mén 'string bag' } \\
\text { imen 'taro' }\end{array}$ & \multirow[t]{2}{*}{ NEUTER 1} \\
\hline & & $\begin{array}{l}\text { liquids, body } \\
\text { fluids/wastes, } \\
\text { substances }\end{array}$ & $\begin{array}{l}\text { aai 'water' } \\
\text { ilem 'blood' } \\
\text { fút 'tobacco' }\end{array}$ & \\
\hline & \multicolumn{2}{|l|}{ places } & $\begin{array}{l}\text { am 'house' } \\
\text { dafáb 'summit' }\end{array}$ & \multirow[t]{7}{*}{ NEUTER 2} \\
\hline & \multicolumn{2}{|l|}{ masses } & $\begin{array}{l}\text { afobèing 'goods, } \\
\text { property' }\end{array}$ & \\
\hline & \multicolumn{2}{|l|}{ body decoration } & $\begin{array}{l}\text { eit 'decoration' } \\
\text { baasi 'pig's tusk' }\end{array}$ & \\
\hline & \multicolumn{2}{|l|}{ weather phenomena } & $\begin{array}{l}\text { sók 'rain' } \\
\text { ayung 'mist' }\end{array}$ & \\
\hline & \multicolumn{2}{|l|}{ illnesses } & kweim 'fever' & \\
\hline & \multicolumn{2}{|l|}{ intangibles/abstracts } & āns 'song' & \\
\hline & \multicolumn{2}{|l|}{ some tools and weapons } & káawa 'steel axe' & \\
\hline
\end{tabular}

${ }^{\mathrm{a}} \mathrm{A}$ subset of nouns shows variation in their gender value mainly depending on the sex of the referent. 
Given the assignment of gender values to nouns as in Table 3, all instances of agreement are determined by the gender, number, and person of the controller. Table 4 summarizes the agreement forms on the article.

Table 4: Agreement forms of the article.

\begin{tabular}{|c|c|c|c|}
\hline \multirow[t]{2}{*}{ GENDER } & \multicolumn{2}{|c|}{ Agreement forms } & \multirow[t]{2}{*}{ Examples } \\
\hline & SINGULAR & PLURAL & \\
\hline \multirow{2}{*}{$\begin{array}{l}\text { MASCULINE } \\
\text { FEMININE }\end{array}$} & $=e$ & \multirow{2}{*}{$=i$} & \multirow{4}{*}{$\begin{array}{l}\text { naka 'man' } \\
\text { unáng 'woman' } \\
\text { tóm 'stone' } \\
\text { am 'house' }\end{array}$} \\
\hline & $=0$ & & \\
\hline NEUTER 1 & $=e$ & \multirow{2}{*}{$=0$} & \\
\hline & $=0$ & & \\
\hline
\end{tabular}

Table 5 sets out the agreement forms of the bound pronouns and the proximal and distal demonstratives. The bound pronouns are used to form, for instance, emphatic pronouns which can function as adnominal determiners in the noun phrase.

Table 5: Bound pronouns (3rd person), proximal, and distal demonstratives.

\begin{tabular}{|c|c|c|c|c|c|c|}
\hline \multirow[t]{2}{*}{ GENDER } & \multicolumn{2}{|c|}{ Bound pronoun } & \multicolumn{2}{|c|}{ Demonstrative (proximal) } & \multicolumn{2}{|c|}{ Demonstrative (distal) } \\
\hline & SINGULAR & PLURAL & SINGULAR & PLURAL & SINGULAR & PLURAL \\
\hline MASCULINE & $\bar{e}-$ & & èle & & $y \bar{e}$ & \\
\hline FEMININE & $\bar{o}-$ & & ōlo & & $y \bar{o}$ & \\
\hline NEUTER 1 & $\bar{e}-$ & & èle & & $y \bar{e}$ & \\
\hline NEUTER 2 & $\bar{o}-$ & & ōlo & 1010 & $y \bar{o}$ & $y 0$ \\
\hline
\end{tabular}

The forms êli and ìli are used interchangeably in adnominal position. There does not seem to be a meaning difference. Demonstratives can also be used pronominally; in pronominal use only êli is possible.

Table 6 lists the agreement forms of the verb. Note the allomorphy in the plural object forms. Recall that seven verbs agree with their object: -têm' 'see (PFV)', -temề' 'see (IPFV)', -lò 'hit, kill (PFV)', -ntamâ' 'bite (PFV)', -fû' 'grab (PFV)' take the marker $y a-$; - $e$ 'hit, kill (IPFV)' takes $y$-; and -nôa' 'hit, kill (PFV)' takes $i$ The recipient object suffixes attach to the verb -ûb- 'give' in the perfective. ${ }^{7}$ The imperfective forms attach to the suppletive stem - $k a$ - 'give (IPFV)'. See Fedden

7 This verb has the allomorphs - $\hat{u} t$ - before $/ \mathrm{n} /$ and $-{ }^{\wedge} b$ - after a vowel. 
Table 6: Verb agreement (3rd person).

\begin{tabular}{|c|c|c|c|c|c|c|c|c|}
\hline \multirow[t]{2}{*}{ GENDER } & \multicolumn{2}{|c|}{ Subject } & \multicolumn{2}{|c|}{ Object } & \multicolumn{2}{|c|}{ Recipient (PFV) } & \multicolumn{2}{|c|}{ Recipient (IPFV) } \\
\hline & SG & PL & SG & PL & SG & PL & SG & PL \\
\hline MASCULINE & $-e$ & ih & $a-$ & (a) & $-a$ & 0 & $-h a$ & \\
\hline FEMININE & -0 & & wa- & & -0 & & $-w e$ & \\
\hline NEUTER 1 & $-e$ & & $a-$ & & $-a$ & & $-h a$ & \\
\hline NEUTER 2 & -0 & & wa- & & -0 & & $-w e$ & \\
\hline
\end{tabular}

(2010) for ditransitives in Mian and for triple agreement on 'give', which agrees with the subject and its two objects (recipient and theme). Both -ûb- and -karequire a classifier for the (theme) object. Classifiers are the topic of the next section.

\section{2 "Classifiers"}

Mian has 37 verbs which require a classifier; these verbs are listed in Appendix A. The forms of the classifiers are given in Table $7 .^{8}$ These classifiers are associated with the object of transitive verbs and the subject of intransitive verbs (of which there is exactly one, namely 'fall'), with assignment according to sex, shape, or function, and they also signal number (see Section 11.2 below).

Table 7 focusses on the forms of the classifiers. We shall discuss the use of these forms in general, and then move on to the complexities of the difference between forms "A" and "B".

8 Most classifiers have phonologically conditioned allomorphs. The FORM A M-, LONG-, and RESIDUE-CLASSIFIERS are realized as do-, to-, and o-, respectively, before /f/ and as dob-, tob-, and $o b$ - elsewhere. There is regressive vowel harmony in $d o b$ - and tob-. The former is realized as $d e b$ - and $d i b$-, before a following syllable nucleus $/ \varepsilon /$ and $/ \mathrm{i} /$, respectively. The latter can be realized as $t a b$ - before a following syllable nucleus $/ \mathrm{a} /$, but tob- is also possible in this context. The FORM B $d o(l)-\sim d l$ - is realized as $d o$ - before $/ \mathrm{s}, \mathrm{k}, \mathrm{h} /, d l$ - before a vowel, and dol- elsewhere. The BUNDLE classifier FORM A and the RESIDUE classifier FORM B forms are realized as go- and $o$ before $/ \mathrm{t}, \mathrm{k}, \mathrm{h} /$ and gol- and ol- elsewhere. The FORM B LONG-, BUNDLE-, and COVERINGCLASSIFIERS are realized as tebel-, gulel-, and gemel-, respectively, before a vowel, and tebe-, gule-, geme- elsewhere. The only classifiers with no allomorphs are om- and gam-, which are invariant in all phonological contexts. We return to the classifiers for 1st and 2nd person in Section 11.1 below. 
Table 7: Forms of the classifiers (3rd person).

\begin{tabular}{|c|c|c|c|}
\hline \multirow[t]{2}{*}{ Assignment criteria } & \multirow[t]{2}{*}{ CLASSIFIER } & \multicolumn{2}{|l|}{ Forms } \\
\hline & & $\begin{array}{l}\text { FORM A } \\
\text { (“SINGULAR") }\end{array}$ & $\begin{array}{l}\text { FORM B } \\
\text { (“NON-SINGULAR") }\end{array}$ \\
\hline males and some inanimates & M-CLASSIFIER & dob- $\sim d o-$ & \multirow{2}{*}{ dol- $\sim$ dl- $\sim$ do- } \\
\hline females and some inanimates & F-CLASSIFIER & om- & \\
\hline long objects & LONG-CLASSIFIER & tob- $\sim$ to- & tebel- tebe- \\
\hline bundle-like objects & BUNDLE-CLASSIFIER & gol- go- & gulel- gule- \\
\hline covering objects & COVERING-CLASSIFIER & gam- & gemel- geme- \\
\hline residue & RESIDUE-CLASSIFIER & $o b-\sim o-$ & ol- $\sim 0$ \\
\hline
\end{tabular}

We use the terms "M-CLASSIFIER" and "F-CLASSIFIER" to distinguish the relevant classifiers from the MASCULINE and FEMININE gender values. While there is a common core and hence some overlap between the MASCULINE gender and the M-CLASSIFIER on the one hand and between the FEMININE gender and the F-CLASSIFIER on the other, genders and classifiers are not coextensive. The terms "M-CLASSIFIER" and "F-CLASSIFIER" have been chosen to reflect the semantic basis of these, since they are assigned to nouns denoting humans and animals of male sex and humans and animals of female sex, respectively.

By default, each Mian noun is associated with just one classifier. The term "default" is meant to refer to the normal use based on inherent or time-stable properties, i.e., when no special properties of the referent are highlighted. For example, a boy is associated with the M-CLASSIFIER by default, but when an infant still attached to the umbilical cord is referred to, the BUNDLE-CLASSIFIER gol- can optionally be used to highlight this temporary property. The default assignment is not necessarily semantically transparent. While the use of min 'son' with the M-CLASSIFIER is semantically motivated, since all nouns with male referents are associated with the M-CLASSIFIER by default, the same cannot be said of the use of the same classifier with youm 'piece of clothing'. The verbs that require a classifier - with a few exceptions - refer to various forms of entity handling or movement, e.g., 'give', 'take', 'put', 'lift', 'turn', 'throw', 'bury', and 'fall'.

We now return to forms "A" and "B", which provide a distinction in NUMBER. This distinction is already surprising, since classifiers typically do not make such a distinction. As is clear from Table 7, there is a NUMBER choice for each classifier. FORM A is straightforwardly SINGULAR. FORM B, 
however, will take further discussion, which we leave for Section 11. For now, suffice it to say that FORM B has different uses, but it never indicates SINGULAR.

\subsection{Interaction between the gender and classifier systems}

Having set out the two candidate systems in Mian, we can now address the question whether the language has one system of nominal classification or two. Let us start with the sets of forms, because they are straightforward. The sets of forms that are used to realize the two candidate systems are clearly different. The forms of the gender system can be found in Tables 4 to 6 , the forms of the classifier system in Table 7. The difference in formal realization was taken as one reason (but not the only one) by Fedden (2011) for analysing Mian as having two systems of nominal classification. However, when we compare the grammatical meanings that underlie each of the candidate systems the separation of systems becomes less clear. If the Mian systems were fully distinct every possible combination of values would be attested. Given that there are four gender and six classifier values we would need to be able to identify 24 combinations. Yet only nine of these are actually found. These will be given later in Table 9. Looking at this from the perspective of assignment, in many cases we can predict the value a noun has in one system, if we know its value in the other system. For example, we can predict that a MASCULINE noun will be associated with the M-CLASSIFIER (e.g., naka 'man') and that a FEMININE noun will be associated with the F-CLASSIFIER (báab 'parent's younger sister'). Similarly, we know that if a noun is associated with one of the LONG-, COVERING-, or BUNDLE-CLASSIFIERS (e.g., geim 'pronged arrow', flim 'palm bark used for flooring', mén 'string bag', respectively), it will be of NEUTER 1 gender. Thus the inter-predictability between the systems is very high. But in some cases our predictions fail, so we cannot say that the classifier system is simply an extended version of the gender system. For example, a noun that is associated with the M-CLASSIFIER can be either MASCULINE (e.g., naka 'man') or NEUTER 1 (e.g., báangkli 'stone adze') and a NEUTER 1 noun can be associated with the RESIDUE classifier (e.g., aful 'ball') or the M-CLASSIFIER (e.g., yóum 'piece of clothing').

\subsection{The problem}

The issue we face is that our overall typology covers the diverse systems we find in the languages of the world and gives Mian a place in it. And yet the typology 
leaves the sense that there is much more to be said about Mian. A strong point of the typology, reflecting Mian's special interest, is that our two criteria for analysing a language as having one system or two point in different directions for Mian. On the one hand, the systems of grammatical meaning cross-cut each other only marginally, suggesting a single system. On the other hand, the sets of forms are distinct, suggesting that there are concurrent systems. In Fedden \& Corbett (2017) we treat Mian as belonging to Type B3, i.e., partial overlap in the semantics and different sets of forms, while pointing out that the orthogonality between the candidate systems is extremely low. This categorization is appropriate in the context of a nine-fold typology of single and concurrent systems, and yet is not sufficient. We require a more fine-grained approach, for which we turn to arguments worked out by Round \& Corbett (2016). We present these arguments in the following section, where we address the questions of why we use features and how we establish the number of features and values.

\section{The logic of differentiating features}

At this point we pause to reflect on why we use features and how we establish the number of features and values. ${ }^{9}$ Let us start with a simpler example than Mian, one which illustrates the issues clearly. Consider the paradigms of two types of Russian noun (Table 8):

Table 8: Forms for Russian gazeta 'newspaper' and žurnal 'magazine'.

\begin{tabular}{lllll}
\hline & SINGULAR & PLURAL & SINGULAR & PLURAL \\
\hline NOMINATIVE & gazeta & gazety & žurnal & žurnaly \\
ACCUSATIVE & gazetu & gazety & žurnal & žurnaly \\
GENITIVE & gazety & gazet & žurnala & žurnalov \\
DATIVE & gazete & gazetam & žurnalu & žurnalam \\
INSTRUMENTAL & gazetoj & gazetami & žurnalom & žurnalami \\
LOCATIVE & gazete & gazetax & žurnale & žurnalax \\
\hline
\end{tabular}

This presentation implies certain claims which are worth examining. We distinguish between concrete lexical meaning and more abstract grammatical meaning. For the appropriate use of gazeta 'newspaper' and žurnal 'magazine' we need rather specific information. On the other hand, the choice between gazeta 'newspaper'

9 We follow the example and discussion in Round \& Corbett (2016), as this path will allow us to introduce and extend the criteria employed there in the discussion of tense-aspect-mood in Kayardild. 
and gazety 'newspapers' depends on more abstract grammatical meaning - number. To model this we use the feature NUMBER, with the values SINGULAR and PLURAL. NUMBER is orthogonal to lexical meaning: the choice between SINGULAR and PLURAL cross-cuts the choice based on lexical meaning; they are different types of information. ${ }^{10}$ So whenever we add a new noun to our account, we do not need to specify the semantic difference between its SINGULAR and PLURAL forms. Thus gazeta 'newspaper' and gazety 'newspapers' are forms of the same lexeme, and they vary for the value of NUMBER.

But NUMBER is not the only feature for which Russian nouns are specified. Russian nouns also make distinctions of CASE. Like NUMBER, the case distinctions are orthogonal to lexical meaning: if we know what gazeta 'newspaper' means, and we know the circumstances in which the GENITIVE is appropriate in Russian, then we know when the GENITIVE of gazeta 'newspaper' can be used. The most important point for us is that, just as NUMBER and CASE are both orthogonal to lexical meaning, so they are orthogonal to each other. We see from Table 8 that each CASE value is found in each NUMBER value, and vice versa; that is, they are fully orthogonal. It is evident that the representation in the table makes sense. An alternative analysis could have a single feature with twelve values, but this would be uneconomical, and would miss seven important considerations that reinforce an analysis treating them as concurrent.

First, the degree of orthogonality of the two candidate systems (CASE and NUMBER) is a key criterion. If we were to take our analysis of Russian further, we would meet additional case values, which are less clear-cut than those given here (Corbett 2012: 200-222). Thus even in this textbook example we do not find full orthogonality. We discuss this criterion with respect to Mian in Section 6.

Second, the orthogonality of the features CASE and NUMBER is reflected first in semantics, where we find (in the canonical instance) compositionality (Section 7). Given the lexical semantics of a lexeme, and the characterization of the feature values in its feature specification, we can predict the meaning of the whole. Coming back to our Russian example, let us assume we know what gazeta means (its lexical semantics); then, if we know the grammatical meaning of PLURAL and of DATIVE, we know the meaning of gazet-am ('newspaper-PL.DAT').

A third aspect of the distinctness of the features NUMBER and CASE in Russian is that they are constrained by different syntactic rules (Section 8). Russian verbs agree with their subject in NUMBER, but not CASE. Conversely, they govern CASE, as do prepositions, and they do so irrespective of NUMBER.

10 We recognize that NUMBER is not fully orthogonal to lexical meaning: there are nouns which lack either the singular or the plural, but there are established regularities as to which these are likely to be in a given language (Corbett 2000: 54-88). 
That is, when we say that a verb governs a particular case value in Russian (e.g., INSTRUMENTAL) we need make no reference to NUMBER: it will govern the INSTRUMENTAL whether the noun is SINGULAR or PLURAL.

Fourth, related to the difference in rules is the issue of distribution: thus going beyond the examples above, features are not distributed equally across parts of speech in Russian; for example there are items (verbs) which show NUMBER but not CASE. If the systems were otherwise identical, this distributional difference would not be a serious issue, but given other differences it is worth considering when we decide whether we have a single or concurrent systems. We take up this fourth issue in Section 9.

Fifth, we consider the issue of exponence. The different forms of the lexemes in Table 8 can be distinguished in terms of their exponents. But while we can distinguish the GENITIVE SINGULAR from the DATIVE SINGULAR in Russian, we cannot pull apart CASE and NUMBER. More specifically, we cannot point to the expression of GENITIVE or DATIVE, since case values in Russian are realized cumulatively with number values. It would further strengthen the analysis in terms of two distinct features, if they could be separated (as happens in languages like Turkish), since the differences in grammatical meaning would be reflected straightforwardly in different forms. We discuss exponence in Section 10.

A sixth criterion - one not used by Round \& Corbett (2016) - is the interaction with a third feature. Thus in Russian, when we examine interactions of CASE and NUMBER with PERSON as the third feature, we find that CASE is relatively straightforward, while PERSON in interaction with NUMBER gives rise to familiar effects of associativity (Corbett 2000: 83-84, 101-111). ${ }^{11}$ The details need not detain us here. The point is that CASE and NUMBER interact somewhat differently with PERSON. More generally, we argue that if the two features we are investigating behave in the same way when interacting with a third, this would count as an argument that we have a single feature, while different interactions would count in favour of an analysis with concurrent features (Section 11).

A seventh argument in favour of the analysis of CASE and NUMBER as distinct features in Russian is provided by typology. A variety of languages display instances like the NUMBER feature of Russian, with or without a CASE feature. Equally we have seen other CASE features like that of Russian, with or without a NUMBER feature. And indeed, there are several languages with NUMBER and CASE interacting in a way similar to that of Russian. The

11 For example, while English robins means 'more than one robin', the 1st person plural pronoun we typically means 'I and associate(s)'. 
typological perspective is invaluable because it helps us avoid suggesting a novel analysis for something that is typologically well-established. Nevertheless, we also need to guard against the danger of forcing a system into a familiar type and missing its particular interest (Section 12).

Our theoretical reason for pursuing nominal classification in Mian is the general point of concurrent systems. We are used to finding languages with systems of different types (like CASE and NUMBER). Equally we know that a particular feature may be present or absent (many languages have a case feature and many do not). But it is unusual to find a language with two concurrent features of the same type, such as two systems of nominal classification as proposed for Mian. Indeed, some instances in which concurrent systems have been suggested can be better analysed as single systems (as claimed by Round \& Corbett (2016) for Kayardild). Yet we do not suggest that concurrent systems are impossible. Rather we are now ready to weigh the evidence for Mian. Does it support an analysis involving concurrent systems, broadly in line with Fedden (2011), or an analysis in terms of a single system? We assess the types of evidence just outlined: the orthogonality of features (Section 6); semantic compositionality (Section 7); syntax (Section 8); distribution (Section 9); exponence (Section 10); interaction with a third feature (Section 11); and typology (Section 12).

\section{Orthogonality of values}

Two features are fully orthogonal if each value of one feature co-occurs with each value of the other; this is what we found with CASE and NUMBER in the data from Russian presented in Table 8: if one feature has six values and the other has two, and we find all 12 combinations of values, then the features are fully orthogonal. Conversely, in the limiting case, features which are not orthogonal have values that correspond one-to-one. For instance, if one feature again had two values and the other also had two, this would yield just two combinations; the value of one "feature" is fully predictable from the other. Given that, we would have to conclude that the evidence from orthogonality offers little support for a two-feature analysis; rather it would be better to analyse them as just one feature. Indeed this is why we did not accept "article gender" and “adjective gender" for French (Section 2.3); they correspond one to one (only the forms differ). ${ }^{12}$

12 We set aside the interesting shape conditions of French. 
Consider now the two candidate systems in Mian. Their degree of orthogonality is actually quite low. Four gender values multiplied by six classifiers yields 24 theoretical possibilities, but only nine of these are attested, as is illustrated in the system matrix (Table 9); the filled cells represent the attested combinations.

When the data are laid out in this way, we see the interest and difficulty of Mian. The semantics (the grammatical meanings) of the two possible systems overlap, but they do not coincide. There are many instances in which we can predict the value a noun has in one system, if we know its value in the other system.

We represent the degree of orthogonality of the two candidate systems by calculating the orthogonality score based on Table 9 (cf. Fedden \& Corbett 2017). In order for the systems to be fully orthogonal all 24 cells would have to be filled. If the systems were non-orthogonal only six cells would be filled. We normalize the score (for Mian in this instance) by deducting the theoretical minimum (six) from the attested number (nine) and dividing this by the theoretically possible maximum (24) minus the minimum (six):

$$
\frac{(\text { cells filled }- \text { minimum cells filled })}{(\text { possible cells }- \text { minimum cells filled })}=\frac{(9-6)}{(24-6)}=\frac{3}{18}=.17
$$

Table 9: Mian gender and classifiers: orthogonality.

\begin{tabular}{|c|c|c|c|c|}
\hline & MASCULINE & FEMININE & NEUTER 1 & NEUTER 2 \\
\hline M-CLASSIFIER & $\begin{array}{l}\text { ‘man', } \\
\text { 'boy', } \\
\text { ‘boar’ }\end{array}$ & - & $\begin{array}{l}\text { 'sleeping bag', 'plate', } \\
\text { 'mosquito net' }\end{array}$ & - \\
\hline F-CLASSIFIER & - & $\begin{array}{l}\text { 'woman', } \\
\text { 'girl', 'sow' }\end{array}$ & - & $\begin{array}{l}\text { 'house', 'steel axe', } \\
\text { 'money (kina note)' }\end{array}$ \\
\hline LONG-CLASSIFIER & - & - & $\begin{array}{l}\text { 'tobacco', 'eating } \\
\text { implement', 'bush knife' }\end{array}$ & - \\
\hline BUNDLE-CLASSIFIER & - & - & $\begin{array}{l}\text { 'string bag (large)', } \\
\text { 'tobacco pouch', 'plastic } \\
\text { bag' }\end{array}$ & - \\
\hline COVERING-CLASSIFIER & - & - & 'blanket', 'band aid' & - \\
\hline RESIDUE-CLASSIFIER & - & $\begin{array}{l}\text { 'tortoise', } \\
\text { 'scorpion' }\end{array}$ & $\begin{array}{l}\text { 'cassowary egg', 'plane', } \\
\text { 'hat' }\end{array}$ & - \\
\hline
\end{tabular}


This formula gives us a measure between 0 (no orthogonality or canonically one system) and 1 (full orthogonality or canonically two systems). At .17, the Mian orthogonality score is relatively low. ${ }^{13}$

It is worth reflecting on this means of analysing potential concurrent systems. The system matrix and the normalized score offer a useful way both of considering individual languages, and of comparing languages (even when there are different numbers of values involved). Clearly, the closer we approach having every cell filled, the nearer we come to having canonically two systems. Furthermore, in the canonical world, not only would the system matrix for concurrent systems have every cell filled, but we would also find the same number of nouns in each (counting types). In the ideal case we would also find the cells equally filled if we counted tokens. That is, canonical concurrent systems would not have skewed distributions: no cells would have few nouns, or be filled with infrequent nouns.

This view of canonicity is putting the bar extremely high. It is evident that in real systems we find different distributions (and we rarely have the detailed data we would like in order to investigate this). For Mian, we have relatively good data, and it is evident that not all the filled cells in Table 9 are equal: as we noted earlier, the cell for the intersection of FEMININE gender and RESIDUE classifier is represented by just three nouns, while some other combinations have a substantial proportion of the noun inventory.

However, the cells are unequal in a rather different way. Imagine that Mian developed a further combination of gender and classifier, i.e., one more cell were filled. Any additional cell would increase the orthogonality score by the same amount. But intuitively, an additional cell in some places in the matrix would be more significant than in others. An additional combination with NEUTER 2, for instance, would change the picture more markedly than one more with FEMININE. Thus in general a cell for a given combination may affect our analysis to a greater or lesser extent.

An alternative representation, a bipartite graph (bigraph), brings out the reason (Figure 1). Figure 1 shows nine edges (linking lines), corresponding to the nine filled cells in Table 9. Figure 1 makes clear that the relations between the two candidate systems are many-to-many. Neither system subsumes the other

13 For comparison, recall the Paumari situation (Table 2) with a $2 \times 2$ system matrix. The calculation would be:

$$
\frac{(\text { cells filled }- \text { minimum cells filled })}{(\text { possible cells }- \text { minimum cells filled })}=\frac{(4-2)}{(4-2)}=\frac{2}{2}=1
$$

This measure suggests that Paumarí has concurrent systems. 
GENDER

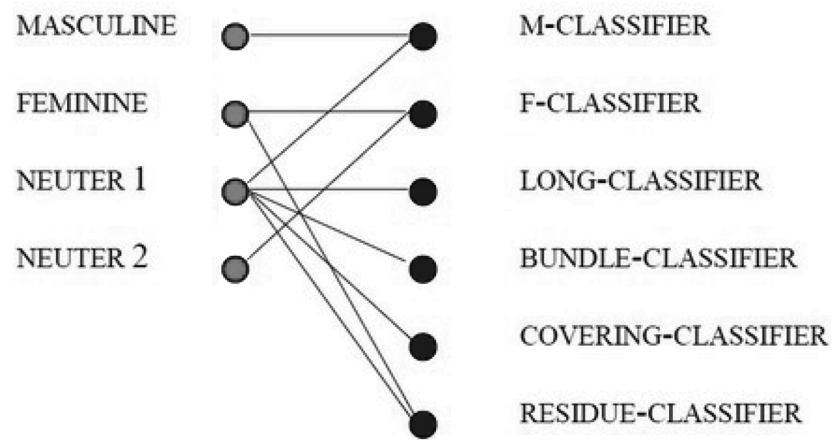

Figure 1: Gender-classifier relations in Mian.

(recall the discussion of inter-predictability in Section 4.3). It is in this sense that cells in Table 9 are not all equal in significance; as we see in Figure 1, some items (like the MASCULINE gender or the LONG-CLASSIFIER) link to a single value (the sign of a single system) while others (like the FEMININE gender or the M-CLASSIFIER) link to many, suggesting concurrent systems.

Figure 1 deals with what is possible/impossible. Such bigraphs are sometimes used to indicate weaker and stronger links. Based on our sample of 894 nouns discussed below, let us treat combinations with fewer than five members as "weak": these would be FEMININE-RESIDUE, NEUTER 1-BUNDLE, and NEUTER 1-COVERING. This is presented in Figure 2.

\section{GENDER}

MASCULINE

FEMININE

NEUTER 1

NEUTER 2

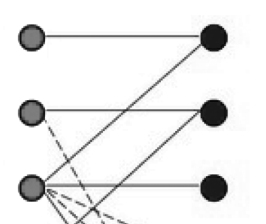

M-CLASSIFIER

F-CLASSIFIER

LONG-CLASSIFIER

BUNDLE-CLASSIFIER

COVERING-CLASSIFIER

RESIDUE-CLASSIFIER

Figure 2: Gender-classifier relations in Mian (making weak links explicit). 
Thus Figure 2 gives a clearer picture of the system. Two comments should be made here. First, concerning the numbers of nouns involved. Some combinations have few members simply because the relevant classifier is limited. Thus there are few nouns which are associated with the BUNDLE-CLASSIFIER, such as mén 'string bag'. The inventory from which these numbers are taken is 894 nouns in total. ${ }^{14}$ And second, these combinations with few members require unique morphological forms. We cannot exclude, say, the nouns taking the BUNDLE-CLASSIFIER as exceptional, since our account of the verbal morphology must include reference to the relevant forms. In other words, we are not dealing with "inquorate" gender values or classifier values (Corbett 2012: 84-85), as discussed in Section 10.

We would like to quantify more precisely the relative strength of the links (edges) in the bigraph, in a way that would facilitate comparison across languages, independent of the number of values in the different systems. We can measure the discrepancy between a putative two-system scheme, as we see in Mian, and a canonical two-system scheme, using our tool "Two systems statistics computation". ${ }^{15}$ This tool is designed specifically for evaluating data where we are interested in the relations between existing systems. While in a fully canonical system we might look for an even distribution of nouns over genders or classifiers, our tool starts from the actual distribution of nouns and calibrates how closely the interaction between the two putative systems approximates a canonical interaction.

Say that there are two systems, $A$ and $B$ (such as gender and classifier). They have possible value $A_{1}, A_{2}, \ldots$ (such as MASCULINE, FEMININE, NEUTER 1 ), $B_{1}, B_{2} \ldots$ (such as M-CLASSIFIER, F-CLASSIFIER, LONG-CLASSIFIER).

We represent type frequencies as a fraction of the whole: $f\left(A_{1}\right), f\left(A_{2}\right)$, and so forth, where $\Sigma f\left(A_{i}\right)=\Sigma f\left(B_{j}\right)=1$. So if most nouns are MASCULINE, we might have $f\left(A_{i}\right)=0.8$ and all the other $f\left(A_{1}\right)$ values are small.

As noted above, this analysis does not expect that $f\left(A_{1}\right)=f\left(A_{2}\right)=\ldots$; there may be any distribution of the frequencies; for instance, the distribution of nouns over shape classifiers will be determined in part by the number of items with the different shapes. What interests us here is the relation BETWEEN the systems, given the distributions WITHIN the systems. In the canonical case, we should find edge frequencies (in the bipartite graph) that respect the type

14 These 894 nouns are the ones for which we have reliable information as to their behaviour regarding nominal classification.

15 Available at http://www.cs.uky.edu/ raphael/linguistics/twoSystems.cgi 
frequencies. So the edge $A_{\mathrm{i}} B_{\mathrm{j}}$ ought to have expected frequency $e\left(A_{i} B_{j}\right)=f\left(A_{i}\right) \times f\left(B_{j}\right)$. In particular, we expect every possible edge to have non-zero expected frequency.

We denote the observed frequencies of each edge $A_{\mathrm{i}} B_{\mathrm{j}}$ as $o\left(A_{\mathrm{i}} B_{\mathrm{j}}\right)$. These observed frequencies may well differ from the expected frequency. The DISCREPANCY of edge $A_{\mathrm{i}} B_{\mathrm{j}}$ is $d\left(A_{i} B_{j}\right)=e\left(A_{i} B_{j}\right)-o\left(A_{i} B_{j}\right)$. Some discrepancies are negative; others are positive. The sum of all discrepancies $\Sigma d\left(A_{i} B_{j}\right)=0$. Therefore, we ignore all negative discrepancies; they are exactly balanced by positive discrepancies. We therefore define the TOTAL DISCREPANCY $T=\frac{1}{2} \Sigma\left|d\left(A_{i} B_{j}\right)\right|$, which is equivalent to summing only the positive discrepancies.

The maximum possible total discrepancy when there are $n$ values in one system and $m$ values in the other one, where $m \geq n$, occurs when there are only $m$ edges in the bipartite graph in a fashion shown in Figure 3. Here, solid lines represent a large number of nouns, and dashed lines represent a vanishingly small number of nouns. Such a scheme clearly has only one system, even though it poses as a two-system scheme. Simple computation shows that $T=1-\frac{1}{n}-\epsilon$. For example, if $n=4$, the maximum possible discrepancy is $T=0.75$, independent of $m$. We can normalize our total discrepancy measure by dividing by this maximum. So for Mian, which has four genders and six classifiers, we set $n=4$, and the maximum possible discrepancy is 0.75. The NORMALIZED TOTAL DISCREPANCY is defined as $N=T /\left(1-\frac{1}{n}\right)=(n T) /(n-1)$. It is always a value between 0 and 1 (inclusive). A value of 0 means no discrepancy; the scheme clearly has two systems. A value of 1 means maximum discrepancy; the scheme clearly has only one system. It is important to keep in mind this scale, running from 0 (two systems) to 1 (one system).

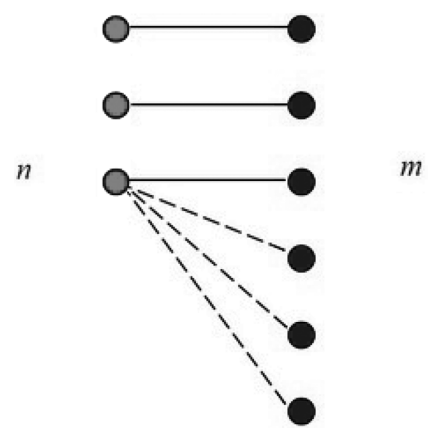

Figure 3: Bipartite graph. 
The data on 894 nouns were elicited primarily by means of a questionnaire, but in a few cases the relevant gender and/or classifier were elicited by direct prompting. ${ }^{16}$ For nouns of common gender, that is those that can be either MASCULINE and take the M-CLASSIFIER, or FEMININE and take the F-CLASSIFIER, we split these equally between the two possibilities. A similar situation arose with tree species, where our consultant, Liden Milimap, treats all trees as NEUTER 1 and associated with the LONG-CLASSIFIER or NEUTER 1 and RESIDUECLASSIFIER. Again we distributed them equally between the two possibilities.

Given those preparations, the normalized total discrepancy is .76. This figure indicates that, on this measure, we are closer to one system than to two.

Recall the intuition noted earlier (and circulated in a draft of this article before we developed the discrepancy measure) that additional combinations of gender and classifier would have different effects. This does find expression in our measure, suggesting that it is a true measure of what we are investigating. Thus if there were Mian', with an additional 50 nouns of the combination NEUTER 2 and LONG-CLASSIFIER, the normalized total discrepancy is .69; that is, more like two systems (which would be expected, since the addition of any additional combination would be expected to have that effect). But if instead we add 50 nouns with the combination FEMININE and LONG-CLASSIFIER, the normalized discrepancy is .71 , that is, there is a smaller effect. Thus an additional combination with NEUTER 2 does indeed change the picture more markedly than one more with FEMININE (demonstrated by keeping the classifier constant for the two gender values). The main point, however, is that we have a measure for orthogonality, which suggests that Mian clearly does not have a straightforward single system, but that it is a long way from having two fully orthogonal systems. (In Appendix B we give comparable measure for Burmeso.)

At this point, the evidence on Mian nominal classification points towards concurrent systems, but the evidence is, perhaps, not fully convincing; we will therefore be looking carefully at the additional tests in Sections 7 to 11 .

\section{Semantic compositionality}

In this section we briefly address the question whether the Mian candidate systems display semantic compositionality. This is what we would expect if the language had two fully orthogonal systems. Ideally we want to hold a

16 In particular, this was to gain confirmation from Liden Milimap that 'blanket', 'band aid', 'skin', and 'palm tree bark' are associated with the COVERING-CLASSIFIER, and that 'scorpion' and the two species of tortoise are associated with the RESIDUE-CLASSIFIER. 
gender value constant and combine it with various classifiers, and check that the contribution of gender is the same in each case; then we should hold the classifier constant and combine it with various gender values and this time check that the contribution of the classifier is the same in each case.

The opportunities to do this for Mian are limited because the degree of orthogonality between the two candidate systems is so low. In all attested combinations, neither the gender nor the classifier change their meanings in the context of the other. To illustrate briefly, the NEUTER 1 noun geim 'pronged arrow' is associated with the LONG-CLASSIFIER tob-, while the NEUTER 1 noun mén 'string bag' is associated with the BUNDLE-CLASSIFIER gol-, but in each case the result is fully compositional, namely NEUTER 1 and LONG-CLASSIFIER for geim 'pronged arrow' and NEUTER 1 and BUNDLE-CLASSIFIER for mén 'string bag'.

A certain semantic independence between the candidate systems can be seen in examples of unusual classifier usage. In the following example (9) a pregnant woman is savaged by a wild boar that tears her open, and throws her unborn son to the ground. Since the foetus is male we would expect the MCLASSIFIER, but instead we find the BUNDLE-CLASSIFIER here:

$\begin{array}{lll}m \bar{e} n=e & y \bar{e} & g o l-\grave{o}-n-e=a \\ \text { child=ART.SG.M there } & \text { 3SG.BUNDLE.OBJ-take.PFV-SEQ-3SG.M.SBJ=MED }\end{array}$

'It (a wild boar) took the boy (with his umbilical cord), and then ...' [Afoksitgabaam]

This usage is impossible if the boy is without the umbilical cord (the usual state), but it is not obligatory if he has it. To use the M-CLASSIFIER dob-yields a grammatical - if less informative - utterance, even if the referent has something attached to him that could be seen as a string or handle and thus justify the use of the BUNDLE-CLASSIFIER gol-.

To sum up, this criterion does not present any evidence against an analysis of Mian in terms of concurrent systems, but it is difficult to use it to argue for such an analysis, given the limited number of opportunities where the semantics could be non-compositional.

\section{Syntax}

In Sections 6 and 7 we looked at the ways in which the two candidate systems behave with respect to one another. Now we ask how each operates syntactically, since this too is germane to the question of whether we indeed have concurrent systems. 
A major morphosyntactic difference between Mian gender and classifiers is that gender agreement shows accusative alignment, whereas the classifiers show absolutive alignment. Consider again the transitive example of gender agreement (10a) and compare with the intransitive sentence in (10b).

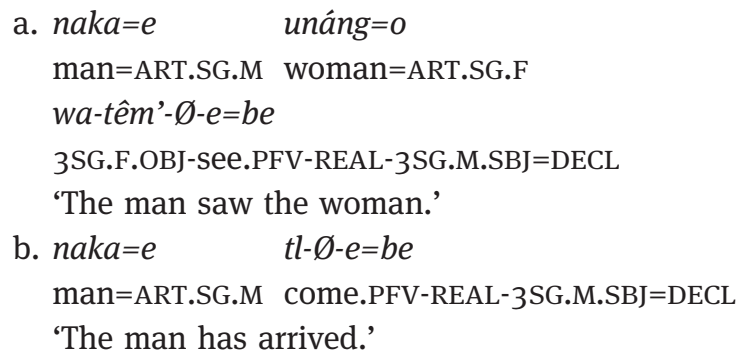

As these examples show, $\mathrm{S}$ is treated like $\mathrm{A}$, and unlike $\mathrm{O}$, so this represents accusative alignment, as evidenced in the agreement of the verb.

Turning to the classifiers, as suggested by their semantics of entity handling or movement, most of the verbs with an obligatory classifier are transitive and their prefixes have a classificatory relation to the object. The only exception to this is -mêin 'fall', an intransitive verb where the relation is to the subject. Hence, the Mian classifiers operate on an absolutive basis, which is illustrated with a transitive clause in (11a) and an intransitive clause in (11b):
a. báangkli=e
$d o b-\grave{o}-n-o=a$
stone.adze=ART.SG.N1 3SG.M_CL.OBJ-take.PFV-SEQ-3SG.F.SBJ=MED
'she took the stone adze and then ...' [Afoksitgabaam]
b. Dabein $=o \quad$ om-mêin $\quad t l-\emptyset$ - $o=t a$
PN=ART.SG.F 3SG.F_CL.SBJ-fall.PFV come.PFV-DS.SEQ-3SG.F.SBJ=MED
'Dabein fell down (i.e., from the sky) and then someone else ...' [Sofelok, 1]

It is important to note that on its own, the existence of different rule types is not necessarily a major issue. After all, a language may have agreement within the nominal phrase, agreement of the verb, and so on, and all of these might deal in the same features (including gender). However, once we have a situation where we need criteria to distinguish between single and concurrent systems, the existence of different rule types, lining up with the different potential systems, is something to take into account.

In sum, the difference in alignment between the candidate systems points to an analysis as concurrent systems. 


\section{Distribution}

We turn to the related issue of the distribution of the relevant inflections. (Here the argument applies slightly differently to the discussion of Kayardild in Round \& Corbett (2016).) There are two points about distribution and they both differentiate the two candidate systems: one is about which parts of speech are involved in either candidate system, the other about the degree to which items of a part of speech are involved in either candidate system (i.e., whether all items within a given part of speech behave alike or not). Of course, we have to be careful and not readily assume that candidate systems that are expressed on different parts of speech automatically form concurrent systems.

We find gender agreement on various parts of speech, namely the article, the free pronouns, of which Mian has various series (cf. Fedden 2011: 124-139), and the verb. The classifiers, on the other hand, appear only on the verb. But the situation is more complicated than this. Apart from the fact that the two candidate systems have different sets of targets, there is a difference in the degree of lexical coverage. Gender is expressed on all possible items, whereas the classifiers occur on a subset of verbs only; the list comprises 37 verbs, most of which have entity handling or movement semantics. ${ }^{17}$ It follows that verbs with classifiers will also agree with the subject in PERSON, NUMBER, and GENDER. There is an additional subtle difference. While all finite verbs agree with their subject, object agreement is restricted to seven verbs (-têm' 'see (PFV)', -temê' 'see (IPFV)', -lò 'hit, kill (PFV)', -ntamâ' 'bite (PFV)', -fû̀' 'grab (PFV)', - $e$ 'hit, kill (IPFV)', and -nâ' 'hit, kill (PFV)'). The set of verbs which take object agreement and the set of verbs which take classifiers is completely distinct, so that there are no verbs which take both object agreement and a classifier.

The criterion of distribution points towards an analysis in terms of concurrent systems.

\section{Exponence}

In the canonical world, each feature value is realized uniformly by one overt, unique exponent in all contexts. Of course, real systems often depart from this

17 Note that the implication is in this direction only. There are further verbs, like mingga 'pull taut' and ngana 'spread out', which could be considered to have handling semantics but which do not take a classifier. 
canonical ideal, and may do so dramatically. In the instances that interest us, there is a considerable difference between the two candidate systems in this respect.

We begin with the gender system. Consider the agreement patterns of the article in Table 10 with different cell shadings for different exponents.

Table 10: Agreement forms of the article.

\begin{tabular}{|c|c|c|c|}
\hline \multirow[t]{2}{*}{ GENDER } & \multicolumn{2}{|c|}{ Agreement forms } & \multirow[t]{2}{*}{ Examples } \\
\hline & SINGULAR & PLURAL & \\
\hline MASCULINE & $=e$ & \multirow{2}{*}{$=i$} & \multirow{4}{*}{$\begin{array}{l}\text { naka 'man' } \\
\text { unáng 'woman' } \\
\text { tóm 'stone' } \\
\text { am 'house' }\end{array}$} \\
\hline FEMININE & $=0$ & & \\
\hline NEUTER 1 & $=e$ & \multirow{2}{*}{$=0$} & \\
\hline NEUTER 2 & $=0$ & & \\
\hline
\end{tabular}

Notice the striking pattern of syncretism. The neuter genders have no agreement forms which are unique to them and are therefore "non-autonomous" values (Zaliznjak 1973: 69-74; Baerman et al. 2005: 15; Corbett 2012: 156). A detailed justification for distinguishing four gender values can be found in Fedden (2007). An alternative two-gender analysis, where all $e$-forms define one gender (MASCULINE) and all $o$-forms define a second gender (FEMININE), is rejected there. The main drawback of such a two-gender analysis for Mian is that it conflates the features NUMBER and GENDER by stipulating that for those nouns that have the $e$-article in the singular and the $o$-article in the plural a change in number is expressed indirectly by a change in gender. Also note that the neuter genders are not inquorate genders in any sense, i.e., genders with just a few nouns in them taking agreements required elsewhere in the system (Corbett 1991: 170). They are not exceptions which could be specified in the lexicon. Rather, there are many hundreds of nouns of NEUTER 1 gender and many dozens of nouns of NEUTER 2 gender, and one or other of the neuter gender values is readily assigned to inanimate loan words.

Nevertheless, the agreements on the targets are fewer in number than one would assume from the statement that Mian has four gender values. The relation between controller genders and target genders is illustrated in Figure 4 using the agreement forms of the article. Mian has four controller genders independent of number. There are two target genders, two distinct agreement possibilities, in both the singular and the plural. 
SINGULAR

PLURAL

e

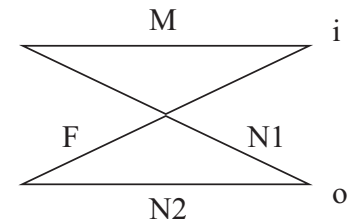

Figure 4: Controller and target genders in Mian.

The situation for the classifiers is very different. The oppositions are given in Table 11, repeated from Table 7, but now leaving out allomorphs to concentrate on the issue at hand. Table 11 suggests that we need to divide nouns into six classes (there are six types of controller) and that similarly there are six distinctions on the verbs which take classifiers. There is no mismatch between the number of classes expressed on controllers and the number of classes expressed on targets (apart from the syncretic form in FORM B, for the M-CLASSIFIER and the F-CLASSIFIER). FORM B is formed by adding a number marker -(e)l to FORM A of the classifier in an almost agglutinative fashion, e.g., gam- vs. gem-el- COVERING-CLASSIFIER, or gol-vs. gul-el- BUNDLECLASSIFIER. There is a vowel change in the LONG-, BUNDLE-, and COVERINGCLASSIFIERS and a stronger degree of fusion between the classifier and the number marker in the RESIDUE-CLASSIFIER, e.g., $o b$ - vs. ol-, and in the M-CLASSIFIER, e.g., dob- vs. dol-. As we shall see in the next section, the

Table 11: Classifiers (3rd person).

\begin{tabular}{|c|c|c|c|}
\hline \multirow[t]{2}{*}{ Assignment criteria } & \multirow[t]{2}{*}{ CLASSIFIER } & \multicolumn{2}{|l|}{ Forms } \\
\hline & & $\begin{array}{l}\text { FORM A } \\
\text { ("SINGULAR") }\end{array}$ & $\begin{array}{l}\text { FORM B } \\
\text { ("NON-SINGULAR") }\end{array}$ \\
\hline $\begin{array}{l}\text { Males and some } \\
\text { inanimates }\end{array}$ & M-CLASSIFIER & $d o b-$ & \multirow{2}{*}{ dol- } \\
\hline $\begin{array}{l}\text { Females and some } \\
\text { inanimates }\end{array}$ & F-CLASSIFIER & om- & \\
\hline Long objects & LONG-CLASSIFIER & tob- & tebel- \\
\hline Bundle-like objects & BUNDLE-CLASSIFIER & gol- & gulel- \\
\hline Covering objects & COVERING-CLASSIFIER & gam- & gemel- \\
\hline Residue & RESIDUE-CLASSIFIER & $o b-$ & ol- \\
\hline
\end{tabular}


situation is more complicated than this table of forms implies; however, the complications are quite different from those of the gender values, and so the evidence of the forms points to a conclusion that the gender and classifier systems are rather different.

The criterion of exponence points towards an analysis of Mian in terms of concurrent systems.

\section{Interaction with other features}

We now turn to a new criterion, one not discussed in Round \& Corbett (2016). If we can find a third feature, with which the candidate features each interact, a difference in the interaction could indicate that the two candidate features are indeed different. In Mian, both of the systems under discussion interact with PERSON and with NUMBER, so it will be interesting to compare the interactions.

\subsection{Interaction with person}

Both candidate systems interact with PERSON. In both systems the full set of distinctions is only made in 3RD PERSON. But both systems have 1ST and 2ND PERSON forms as well. We first consider the interaction of GENDER with PERSON on the verb (Table 12).

Table 12: GENDER and PERSON (target: verb).

\begin{tabular}{|c|c|c|c|c|c|c|c|c|c|}
\hline \multirow[t]{2}{*}{ PERSON } & \multirow[t]{2}{*}{ GENDER } & \multicolumn{2}{|c|}{ Subject } & \multicolumn{2}{|c|}{ Object } & \multicolumn{2}{|c|}{ Recipient (PFV) } & \multicolumn{2}{|c|}{ Recipient (IPFV) } \\
\hline & & SG & PL & SG & PL & SG & PL & SG & PL \\
\hline \multicolumn{2}{|l|}{1} & $-i$ & $-a b$ & na- & \multirow{4}{*}{$y(a)-\sim i-$} & $-n e$ & \multirow{4}{*}{$-e$} & $-n e$ & \multirow{4}{*}{$-y e$} \\
\hline 2 & & $-e b$ & \multirow{3}{*}{$-i b$} & ka- & & $-k e$ & & $-k e$ & \\
\hline \multirow[t]{4}{*}{3} & \multirow{2}{*}{$\begin{array}{l}\text { MASCULINE } \\
\text { FEMININE }\end{array}$} & $-e$ & & $a-$ & & $-a$ & & $-h a$ & \\
\hline & & -0 & & wa- & & -0 & & -we & \\
\hline & NEUTER 1 & $-e$ & \multirow{2}{*}{-0} & $a-$ & \multirow{2}{*}{ wa- } & $-a$ & \multirow{2}{*}{-0} & $-h a$ & \multirow{2}{*}{$-w e$} \\
\hline & NEUTER 2 & -0 & & wa- & & -0 & & $-w e$ & \\
\hline
\end{tabular}


The Mian verb agrees with up to three arguments in PERSON, NUMBER, and GENDER. For the recipient object, there are two partially overlapping sets of forms depending on aspect. There is some syncretism across PERSON values in the PLURAL and there is a distinct 1ST PERSON PLURAL form for subject agreement, but interaction of GENDER with PERSON is straightforward. When we look at the free pronouns and the bound pronoun roots, i.e., pronoun roots which serve as bases for different series of derived pronouns, we find a similarly straightforward interaction, except that the 2ND PERSON pronouns allow a MASCULINE-FEMININE contrast to be encoded also (Table 13). As we would expect from a pronoun system there is no syncretism across PERSON here.

Table 13: GENDER and PERSON (targets: free pronoun and bound pronoun roots).

\begin{tabular}{|c|c|c|c|c|c|}
\hline \multirow{2}{*}{ PERSON } & \multirow{2}{*}{ GENDER } & \multicolumn{2}{|c|}{ Free pronoun } & \multicolumn{2}{|c|}{ Bound pronoun roots } \\
\hline & & SINGULAR & PLURAL & SINGULAR & PLURAL \\
\hline \multicolumn{2}{|l|}{$1 \mathrm{EXCL}$} & $n \bar{e}$ & $n \bar{\imath}$ & $n \bar{e}-$ & $n \overline{-}$ \\
\hline \multicolumn{2}{|l|}{$1 \mathrm{INCL}$} & & nībo & & $n \bar{b} b-$ \\
\hline \multirow[t]{2}{*}{2} & MASCULINE & kōbo & \multirow{2}{*}{ ībo } & $k \bar{e} b-$ & \multirow{2}{*}{$\bar{i} b-$} \\
\hline & FEMININE & $\bar{o} b o$ & & $\bar{o} b-$ & \\
\hline \multirow[t]{4}{*}{3} & MASCULINE & $\bar{e}$ & \multirow{2}{*}{$\bar{I}$} & $\bar{e}-$ & \multirow{2}{*}{$\bar{i}-$} \\
\hline & FEMININE & $\bar{o}$ & & $\bar{o}-$ & \\
\hline & \multirow[t]{2}{*}{ NEUTER 1} & $\bar{e}$ & $\bar{o}$ & $\bar{e}-$ & \multirow{2}{*}{$\bar{o}-$} \\
\hline & & $\bar{o}$ & $\bar{o}$ & $\bar{o}-$ & \\
\hline
\end{tabular}

Let us now turn to the interaction of classifiers with PERSON. Here the only relevant part of speech is the verb, since the classifiers only appear on (a subset of) verbs (Table 14). For the difference between FORMS A ("SINGULAR") and B ("NON-SINGULAR"), see Section 4.2. This issue will be taken up in more detail in Section 11.2, where we discuss the interaction between the candidate systems and NUMBER.

While there is only a single form for the 1ST and 2ND PERSONS in the PLURAL, together with the M-CLASSIFIER and the F-CLASSIFIER, as seen in (12), there are unique forms for the 1ST and 2ND PERSON SINGULAR, in (13). 
Table 14: CLASSIFIER and PERSON (verb).

\begin{tabular}{|c|c|c|c|c|}
\hline \multirow[t]{2}{*}{ PERSON } & \multirow[t]{2}{*}{ Assignment criteria } & \multirow[t]{2}{*}{ CLASSIFIER } & \multicolumn{2}{|l|}{ Forms } \\
\hline & & & $\begin{array}{l}\text { FORM A } \\
\text { ("SINGULAR") }\end{array}$ & $\begin{array}{l}\text { FORM B } \\
\text { ("NON-SINGULAR") }\end{array}$ \\
\hline 1 & & 1-CLASSIFIER ${ }^{a}$ & nem- & \multirow{4}{*}{ dol- } \\
\hline 2 & & 2-CLASSIFIER & kem- & \\
\hline \multirow[t]{6}{*}{3} & $\begin{array}{l}\text { males and some } \\
\text { inanimates }\end{array}$ & M-CLASSIFIER & dob- & \\
\hline & $\begin{array}{l}\text { females and some } \\
\text { inanimates }\end{array}$ & F-CLASSIFIER & om- & \\
\hline & long objects & LONG-CLASSIFIER & tob- & tebel- \\
\hline & bundle-like objects & $\begin{array}{l}\text { BUNDLE- } \\
\text { CLASSIFIER }\end{array}$ & gol- & gulel- \\
\hline & covering objects & $\begin{array}{l}\text { COVERING- } \\
\text { CLASSIFIER }\end{array}$ & gam- & gemel- \\
\hline & residue & $\begin{array}{l}\text { RESIDUE- } \\
\text { CLASSIFIER }\end{array}$ & $o b-$ & ol- \\
\hline
\end{tabular}

${ }^{a}$ We call these 1-CLASSIFIER and 2-CLASSIFIER to distinguish these from the markers that are part of the ordinary person and number system.

(12)

$\begin{array}{lll}n \bar{l}=l e & n a k a=i & \text { asusûna=i } \\ \text { 1PL.EXCL=TOP } & \text { man=ART.PL.AN } & \text { two=ART.PL.AN } \\ d l-\hat{e} t-n-i b=a & & \end{array}$

1PL_CL.OBJ-take.PFV-SS.SEQ-2/3PL.AN.SBJ=MED ${ }^{18}$

'as for us, the two men took us and then ...' [Ala ritual]

(13) a. nem-suan- $b-e o=b e$

1SG_CL.OBJ-hate.IPFV-IPFV-2SG.SBJ=DECL

'You hate me.'

b. kem-suan- $b$ - $i=b e$

2SG_CL.OBJ-hate.IPFV-IPFV-1SG.SBJ=DECL

'I hate you.'

What we find for the classifier system is a very similar interaction with person compared to what we had in the gender system. One difference is that distinctions in the classifier system are restricted to 3rd person, while in the

18 The justification for glossing $d l$ - as 1ST PERSON PLURAL will be given in Section 11.2 below. 
gender system, 2nd person pronouns allow a proper subset of the gender values to be expressed. However, this possibility is not open to the classifier system, since it does not have free pronouns, so this is a difference in the range of targets, not in terms of interaction with person.

In summary, the ways in which gender and classifiers interact with person are similar, which gives no support to an analysis of Mian in terms of concurrent systems.

\subsection{Interaction with NUMBER}

We move on to discuss interaction of the candidate systems with NUMBER. Consider first the interaction of GENDER with NUMBER. Here the situation is roughly as we would expect. We noted earlier (Section 10) the interesting pattern of syncretism. Nevertheless, we find that GENDER and NUMBER are relatively independent of each other. Typically nouns in the different genders appear in both SINGULAR and PLURAL. As anticipated, there are also some nouns, at the bottom of the Animacy Hierarchy, which fall below the threshold for number differentiability in Mian, and these are singularia tantum. They include abstract nouns like fotom 'shame', weather phenomena like sók 'rain', or illnesses like kweim 'fever'. These nouns all belong in the NEUTER 2 gender. However, we also need to mention the small set of countable nouns in the NEUTER 2 gender; these include am 'house' and káawa 'steel axe'. Recall that the agreements are the same for SINGULAR and PLURAL $(=0,=0)$, so the number value of these nouns is not reflected on the article or the verb (nor is it shown on the noun itself). These nouns are count nouns, however, as shown by their use with numerals. Furthermore, they make a number distinction through the classifiers.

When we turn to the interaction of the classifiers with NUMBER, we find a remarkable situation. Of course, we do not expect classifiers to have NUMBER. ${ }^{19}$ Yet in Mian all six classifiers have two forms, which we have so far labelled FORM A (SINGULAR) and FORM B (NON-SINGULAR). We now turn to the use of these forms. Consider first their use with animates (Table 15), leaving out allomorphs.

19 A rare case of a number contrast in classifiers is attested in Weining Ahmao, a Miao-Yao language of China (Gerner \& Bisang 2008, 2009). 
Table 15: Classifiers for animates.

\begin{tabular}{|c|c|c|c|}
\hline PERSON & CLASSIFIER & $\begin{array}{l}\text { Forms } \\
\text { SINGULAR }\end{array}$ & PLURAL \\
\hline 1 & 1-CLASSIFIER & nem- & \multirow{4}{*}{ dol- } \\
\hline 2 & 2-CLASSIFIER & kem- & \\
\hline \multirow[t]{3}{*}{3} & M-CLASSIFIER & $d o b$ & \\
\hline & F-CLASSIFIER & om- & \\
\hline & RESIDUE-CLASSIFIER & $a b-$ & ol- \\
\hline
\end{tabular}

The picture is straightforward. For animates the number opposition in the classifiers is always one between SINGULAR and PLURAL. This is illustrated in (14):
(14)
a. éil=e
do- $f \hat{a}-n-e b o=b e$
pig=ART.SG.M 3SG.M_CL.OBJ-put.PFV-REAL-2SG.SBJ=DECL
'You put a boar down.'
b. éil=i
$d l-\hat{a}-n-e b o=b e$
pig=ART.PL.AN 3PL.M_CL.OBJ-put.PFV-REAL-2SG.SBJ=DECL
'You put boars down.'

The RESIDUE-CLASSIFIER is special in that it is used both with animate and inanimate nouns. While most are inanimate there are three nouns that are animate, namely maabsêi 'tortoise species', maabtôm 'tortoise species', and takumein hok 'scorpion'. The LONG-, BUNDLE-, and COVERING-CLASSIFIERS on the other hand are exclusively used with inanimates.

When we turn then to the inanimates (irrespective of the classifier they take) the situation becomes truly surprising. With inanimate nouns, the forms of the classifiers glossed as FORM B in Table 11 (repeated from Table 7), indicate a PAUCAL. And the FORM B of the RESIDUE-CLASSIFIER ol-is used for the PLURAL. In (15) monî 'money' takes the F-CLASSIFIER in FORM A, and we have the expected singular meaning.
(15) $\quad m o n \hat{\imath}=O$
om-ût'-ne!
money=ART.N2 3SG.F_CL.OBJ-give.PFV-1SG.R
'Give me the coin/banknote!'

In (16) the "right" classifier is retained, but in FORM B: 
(16)

monî̀=o dl-ût'-ne!

money=ART.N2 3PAUCAL.F_CL.OBJ-give.PFV-1SG.R

'Give me a few coins/banknotes!'

The effect, with inanimates like monî 'money', is that we have a PAUCAL (a few). In order to express PLURAL, the "wrong" classifier, the RESIDUE CLASSIFIER, in FORM B is used, as in (17):
(17) $m o n \hat{\imath}=O$
ol-ût'-ne!
money=ART.N2 3PL.RESD.OBJ-give.PFV-1SG.R
'Give me some coins/banknotes!' (more than a few)

Having seen the behaviour of the NEUTER 2 noun monî 'money', this is a good place to give our reasons why we do not treat the nouns presently analysed as NEUTER 2 as pluralia tantum nouns of NEUTER gender. This would simplify the gender system while complicating the number system. It seems to be a plausible analysis from a semantic point of view, because some of the nouns in question refer to masses, e.g., afobèing 'goods, property', or entities which could be viewed as consisting of several parts, e.g., am 'house' or káawa 'steel axe'. Some of these are count nouns, and it is possible to say káawa olokiêm 'one steel axe', but this does not immediately undermine the pluralia tantum analysis since we could analyse olokiêm as the plural form of the numeral elekiêm 'one'. This is in fact the form that we would expect, given that for neuter nouns which make a singular-plural distinction (NEUTER 1) the forms of the proximal demonstrative are èle 'this' and ōlo 'these'. ${ }^{20}$

While a pluralia tantum analysis of NEUTER 2 nouns is workable within the gender system, in which we could simply treat these nouns as NEUTER and PLURAL-only, we reject such an analysis for Mian based on evidence from the behaviour of these nouns within the system of classifiers. We have seen that the classifiers are capable of encoding a SINGULAR-PAUCAL-PLURAL distinction for NEUTER 2 nouns, such as monî 'money'. This is clearly unexpected if nouns like monî were pluralia tantum. This is rather different from the use of special numeral forms. The SINGULAR-PAUCAL-PLURAL distinction runs through the full classifier system, and the regular forms are used (there are no special forms for the nouns we are considering here). These nouns form a large proportion of the nominal lexicon: there are hundreds of such nouns in Mian. Given all

20 We find a similar phenomenon in Russian where the plurale tantum noun sani 'sledge' can be counted, and modified with the numeral 'one' as well, but in its plural form odni, hence odn-i sani [one-PL sledge] 'one sledge'. 
these points we reject the pluralia tantum analysis for these nouns and retain the analysis of them as constituting a separate gender value (NEUTER 2).

The pattern seen in (15) to (17), SINGULAR, PAUCAL, and PLURAL, applies to all inanimate nouns (apart from those which occur with the RESIDUE-CLASSIFIER, where PAUCAL and PLURAL cannot be differentiated). The prefixes tebel- (LONG), gemel(COVERING), and gulel- (BUNDLE) are used to express PAUCAL rather than PLURAL.

As another example, the noun geim 'pronged arrow' is classified by default as LONG. However, when reference is made to more than a few of these arrows, the RESIDUE prefix ol- is used. Compare (18a) and (18b). The article $=o$ following the noun geim 'pronged arrow' signals PLURAL while the choice of classifier form determines the reading as PAUCAL or PLURAL.

a. kōbo geim=o

tebel-ûbma

2SG.M pronged.arrow=ART.PL.N1 3PAUCAL.LONG.OBJ-turn.around

tebelâbma bi-Ø-ebo=be

REDUP exist.IPFV-IPFV-2SG.SBJ=DECL

'You are turning around a few pronged arrows in your hands.'

b. kōbo geim=o ol-ûbma olâbma

2SG.M pronged.arrow=ART.PL.N1 3PL.RESD.OBJ-turn.around REDUP

$b i-\emptyset-e b o=b e$

exist.IPFV-IPFV-2SG.SBJ=DECL

'You are turning around many pronged arrows in your hands.'

The pattern is shown in Table 16.

Table 16: Classifiers for inanimates.

\begin{tabular}{|c|c|c|c|}
\hline \multirow[t]{2}{*}{ CLASSIFIER } & \multicolumn{3}{|l|}{ Forms } \\
\hline & SINGULAR & PAUCAL & PLURAL \\
\hline M-CLASSIFIER & $d o b-$ & & \multirow{6}{*}{ ol- } \\
\hline F-CLASSIFIER & om- & & \\
\hline LONG-CLASSIFIER & tob- & tebel- & \\
\hline BUNDLE-CLASSIFIER & gol- & gulel- & \\
\hline COVERING-CLASSIFIER & gam- & gemel- & \\
\hline RESIDUE-CLASSIFIER & $o b-$ & & \\
\hline
\end{tabular}

This is interesting and surprising. First, the key point is that this number distinction in the classifiers is not found in the gender system. Thus CLASSIFIERS 
and GENDER behave differently in interaction with NUMBER, in that they establish different sets of contrasts, which is an argument for analysing GENDER and CLASSIFIERS as concurrent systems.

Having a SINGULAR-PAUCAL-PLURAL number system is in any case rare; while many languages have a PAUCAL (particularly in the Austronesian family), the PAUCAL is almost always found together with a DUAL. One well-studied example of the rarer system (without a DUAL) is the Cushitic language Bayso (Corbett \& Hayward 1987). This language has a separate GENERAL number value in addition to SINGULAR, PAUCAL, and PLURAL. According to Savà (2011: 183) there is also a PAUCAL in Bayso's neighbour Haro. Further afield, the Guaicuruan language Mocoví has SINGULAR-PAUCAL-PLURAL (Grondona 1998: 11, 52-60). ${ }^{21}$

We may wonder about the animate-inanimate split. Recall that animates have SINGULAR-PLURAL while inanimates have SINGULAR-PAUCAL-PLURAL. While this is perhaps surprising, it fits within the typology of number. Various languages have distinct systems involving the top of the Animacy Hierarchy (socalled "top systems") and lower parts of the hierarchy ("second systems"), as demonstrated in Corbett (2000: 120-124). Mian fits this typology, in having a normal system (SINGULAR-PLURAL) as its top system, and the unusual SINGULAR-PAUCAL-PLURAL as its second system, employed for inanimates. There are also, as discussed earlier, nouns which fall below the number differentiability threshold and have no number opposition; these constitute the "bottom system", as shown in Figure 5.

\begin{tabular}{|c|c|c|c|}
\hline $\begin{array}{l}\text { Range of PLURAL } \\
\text { Range of PAUCAL } \\
\text { System }\end{array}$ & 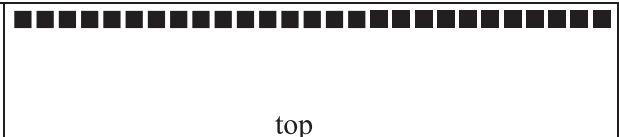 & 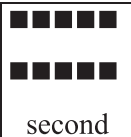 & bottom \\
\hline
\end{tabular}

Figure 5: Number value systems of Mian.

Thus in this respect, in the distribution of systems of oppositions, NUMBER in Mian fits our expectation. And, to reiterate our main point, it shows clearly a way in which GENDER and CLASSIFIERS differ in Mian. We may still ask how this extra number value for inanimates could have arisen. ${ }^{22}$ As we shall see, we need to piece together rather disparate clues.

21 We are grateful to Daniel Harbour for bringing Mocoví to our attention.

22 "[...] though there are some significant studies, relatively little detailed work has been done on the rise of number systems, and there are no doubt some surprises in store" (Corbett 2000: 266). Mian represents quite a surprise. 
Starting with the origins, the etymology of the Mian classifiers is unclear. With the exception of the COVERING-CLASSIFIER gam-, which seems to be related to the clitic postposition gam 'covered with' (e.g., $\mathrm{klo}=$ = gam [ringworm=covered. with] 'covered with ringworm'), none of the other classifiers can synchronically be traced to any lexical item. Looking further afield, complex systems of the Mian type with shape- or function-based semantics are not attested in the other Mountain Ok languages. However, there are plausible cognates in Mountain Ok for the M- and F-CLASSIFIERS; these cognates are analysed as special object agreement prefixes that only occur with a subset of verbs. Verbs in this subset agree with their objects in PERSON, NUMBER (SINGULAR vs. PLURAL), and GENDER (MASCULINE vs. FEMININE). This is the analysis for Telefol (Healey 1965: 12), for Faiwol (Healey 1964: 70), for Tifal (Boush 1975), and for Bimin (Weber 1997). The forms are given in Table 17; prefixes which are unlikely to be cognate with the Mian forms (dob-, om-, dol-) are marked ${ }^{\mathrm{x}}$.

Table 17 covers all Mountain Ok languages, so we conclude that the extended Mian system is an innovation. There may have been two types of system: Type 1 in Telefol and Faiwol (both with kub- and kul-); and Type 2 in Mian (om-), Tifal (um-), and Bimin (wam-). However, the key changes appear to have taken place within the development of Mian. Our clues must come from Mian-internal evidence, and from the typology of number systems.

We suggest that an early stage in the development of Mian may have been rather like the position in Table 15, except that this was the total system, with $d o b$ - and om- for animates and $o b$ - for inanimates. The system was thus, we suggest, very similar to the GENDER system, and as with GENDER this was crosscut by a straightforward opposition of SINGULAR versus PLURAL.

Table 17: Prefix forms in Telefol, Faiwol, Tifal, and Bimin.

\begin{tabular}{|c|c|c|c|c|}
\hline & & SINGULAR & PLURAL & Source \\
\hline \multirow[t]{2}{*}{ Telefol } & MASCULINE & $d u b-\sim d u-$ & dul- & \multirow{2}{*}{ Healey (1965: 12) } \\
\hline & FEMININE & ${ }^{x} k u b-\sim k u-$ & x kul- & \\
\hline \multirow[t]{2}{*}{ Faiwol } & MASCULINE & $d u b$ - & dul- & \multirow{2}{*}{ Healey (1964: 70) } \\
\hline & FEMININE & ${ }^{x} k u b-$ & x $k$ kul- & \\
\hline \multirow[t]{2}{*}{ Tifal } & MASCULINE & $d a b-$ & \multirow{2}{*}{ no data } & \multirow{2}{*}{ Boush (1975: 13-14) } \\
\hline & FEMININE & um- & & \\
\hline \multirow[t]{2}{*}{ Bimin } & MASCULINE & daw- & \multirow{2}{*}{ no data } & \multirow{2}{*}{ Weber (1997) } \\
\hline & & wam- & & \\
\hline
\end{tabular}


The next stage involves the development of the other classifiers; as we noted, their etymology is unclear. And there is the question of the grammatical meanings of the forms we earlier labelled FORM B. We suggest that these forms were then plurals, as in Table 18.

Table 18: Stage 2 (hypothetical): the development of the classifiers.

\begin{tabular}{|c|c|c|c|c|}
\hline \multirow[t]{2}{*}{ PERSON } & \multirow[t]{2}{*}{ Assignment criteria } & \multirow[t]{2}{*}{ CLASSIFIER } & \multicolumn{2}{|l|}{ Forms } \\
\hline & & & $\begin{array}{l}\text { FORM A } \\
\text { ("SINGULAR") }\end{array}$ & $\begin{array}{l}\text { FORM B } \\
\text { (“PLURAL") }\end{array}$ \\
\hline 1 & & 1-CLASSIFIER & nem- & \multirow{4}{*}{ dol- } \\
\hline 2 & & 2-CLASSIFIER & kem- & \\
\hline \multirow[t]{6}{*}{3} & males and some inanimates & $M$-CLASSIFIER & $d o b-$ & \\
\hline & females and some inanimates & F-CLASSIFIER & om- & \\
\hline & long objects & LONG-CLASSIFIER & tob- & tebel- \\
\hline & bundle-like objects & BUNDLE-CLASSIFIER & gol- & gulel- \\
\hline & covering objects & COVERING-CLASSIFIER & gam- & gemel- \\
\hline & residue & RESIDUE-CLASSIFIER & $o b-$ & ol- \\
\hline
\end{tabular}

Why do we believe that forms like tebel- and gulel- were plurals? Primarily for typological reasons. We do not find systems consisting just of SINGULAR and PAUCAL, but we do of course find SINGULAR-PLURAL systems. We now have to explain the development from this Stage 2 to the current situation (as in Table 16), where the ol- form is the plural for all the inanimates. There are two pieces of evidence which we believe make this development of $o l$ - plausible. The first concerns situations where items of different types (requiring different classifiers) are involved. In the modern language (and we hypothesize already at the time of the development from Stage 2), for such mixtures the RESIDUE-CLASSIFIER is used, as in (19):

$$
\begin{aligned}
& \text { ne geim=o asumâtna eka mén=o } \\
& \text { 1SG pronged.arrow=ART.PL.N1 three and string.bag=ART.PL.N1 } \\
& \text { asú eka két=o asumâtna ol-êb } \\
& \text { two and jerrycan=ART.PL.N1 three 3PL.RESID.OBJ-carry.PFV } \\
& \text { un- } \emptyset-i=b e
\end{aligned}
$$$$
\text { go.PFV-REAL-1SG.SBJ=DECL }
$$

'I carry away three pronged arrows, two string bags, and three jerrycans.' 
Thus the RESIDUE-CLASSIFIER has a special status, being more generally available than the others.

The second piece of evidence concerns the lexical semantics of the verbs involved. They include verbs of object manipulation and movement involving the hands. Such verbs are likely to involve a handful of items, quite literally. Thus, we suggest, while the B forms were available at Stage 2 for any number of items above one, many of the actual uses would involve small numbers of items. Hence on the one hand ol- is available for all items, and remains PLURAL, while forms like tebel- are reduced to PAUCAL use.

It may be asked why the RESIDUE-CLASSIFIER does not develop a distinct PAUCAL too. One possible reason is that it still operates in the animacy system (Table 15), where the opposition remains SINGULAR-PLURAL.

Our hypothesis remains within the known typology of number systems, and has some plausibility based on the facts of the modern language. ${ }^{23}$ The interaction of gender and number in Mian is standard. That of classifiers and number is extraordinary. For our purposes, the key point is that these two interactions are different. And this is an argument that gender and classifiers are concurrent systems in Mian.

\section{The typological argument}

Since we are proposing a typology, we must justify having an additional typological argument, and of course we must beware of circularity. To see the shape of a possible argument, we return to the Russian opposition of NUMBER and CASE (Section 5). To suggest that Russian has both a CASE feature and a NUMBER feature would not distress Ockham, since both are already needed for the description of other languages. Specifically for Russian, it is reasonable to say that the case system looks like a case system crosslinguistically, and the number system is like one we have seen many times. Moreover, the two vary independently: there are languages which have a case system comparable to that of Russian, but with a rather different number system. Equally there are many

23 Other possible comparisons are of varying relevance. There are instances of paucals "moving up" to become plurals, but this is in larger systems, those including a separate dual (Corbett 2000: 268-269). The paucal in the Cushitic language Bayso is of interest (Corbett \& Hayward 1987: 1718). There it appears that the paucal is an innovation; it is probably a plural marker in origin, and it has more regular marking than the synchronic plural. But in Bayso, the paucal is marked on nouns (and has surprising agreements), which is quite unlike the Mian classifiers. Finally there are intriguing comparisons with the paucal and plural (often referred to as $2+$ and $3+$ ) in the verbal classifiers of Navajo, for which see Unterbeck (2000: 438-449) and references there. 
languages with a comparable singular-plural number system, some of them with case systems and some without.

Returning then to Mian, the "gender" system has many characteristics shared with other gender systems. The "classifier" system too shares properties with other systems of verbal classifiers; for instance, crosslinguistically, verbal classifiers are only found with this ergative-absolutive alignment type (Keenan 1984: 203-204). We might propose this as a further argument for concurrent systems in Mian.

There is, however, a more challenging view. In some respects the "classifiers" of Mian look rather like a gender system. Indeed, if we had presented just this system, we could have described it as a limited and somewhat unusual gender system. And this is part of a more general observation: in our view, it is no longer possible to draw a dividing line between gender systems and classifier systems, and treat them as opposites. Rather we can define a canonical gender system, and calibrate the various disparate phenomena which have been termed classifiers with respect to this canonical point (Corbett \& Fedden 2016; see also Singer forthcoming).

Where does this leave the argument about concurrency? We can no longer appeal to the argument (in favour of a concurrent analysis) that depends on recognizing instances of two different types of feature in a single language. This is because it is no longer evident that the "classifier" system of Mian is different in type from the gender system. However, this argument does not count against a concurrent analysis either. This is because there are instances of concurrent systems which involve two features of the same type. We discussed one, namely Paumarí, in Section 3. ${ }^{24}$ Given that concurrent systems of the same type can exist, the typological argument does not tip the balance for Mian in either direction.

\section{Conclusions}

We offer some conclusions about the analysis of Mian nominal classification (Section 13.1), the typology of feature systems (Section 13.2), and the typology of concurrent systems (Section 13.3).

24 A further possible example is Michif. This mixed language is claimed to have an animateinanimate gender system combined with a masculine-feminine gender system. These two systems occur together in the noun phrase. The original research on this language can be found in Bakker \& Papen (1997) and Bakker (1997), and the data on gender are discussed in Corbett (2006: 269-270; 2012: 176). 


\subsection{For the analysis of nominal classification in Mian}

The starting point of our analysis was the remarkable nominal classification found in Mian, and its place in the typology of single and concurrent systems. We had previously analysed Mian's candidate systems as showing partially overlapping semantics and different formal realizations; we concluded that Mian has concurrent systems, a Type B3 according to Fedden \& Corbett (2017). As the low orthogonality score of .17 made this judgement less than fully secure we have considered six further criteria in this article, five of which point towards an analysis of the Mian candidate systems as concurrent, while the sixth is inconclusive. Evidence from semantic compositionality (Section 7) is scant because of the restricted combinability of the candidate systems, but from the cases that are possible we saw that the meanings can be computed compositionally. This points in the direction of concurrent systems. We find more support for the concurrent analysis by looking at the syntax (Section 8). The candidate systems differ with respect to their morphosyntactic alignment. The Mian gender system operates on an accusative basis, while the classifier system operates on an absolutive basis. Further, the distribution of the systems across parts of speech differs (Section 9). The gender system has a range of targets on which its values are expressed (verb, pronouns, articles). The classifiers exclusively appear on a subset of verbs. Further differences between the candidate systems are their behaviour with respect to exponence (Section 10). The gender system shows considerable syncretism which leads to a situation in which we find a discrepancy between the number of controller genders (four, namely MASCULINE, FEMININE, NEUTER 1, and NEUTER 2) and the number of target genders (just two distinct forms in each number). In the classifiers, on the other hand, we do not find such a discrepancy. While the two systems show similar patterns of interaction with PERSON, they have very different patterns of interaction with NUMBER (Section 11). The gender system takes part in a straightforward SINGULAR-PLURAL opposition, but the classifiers have an additional PAUCAL (in the absence of a DUAL) for inanimates, which we believe is an innovation in Mian. Finally, the typological argument proved inconclusive in terms of deciding between single or concurrent systems (Section 12).

The new evidence thus supports the analysis presented in Fedden \& Corbett (2017) of Mian as a language with concurrent systems of nominal classification. While the arguments point one way, they do so somewhat weakly in some instances, and the two systems show significant areas of overlap. 


\subsection{For the typology of feature systems}

There is a view, which we may call the "No Concurrent Features Conjecture" (Round \& Corbett 2016), according to which a language may or may not have each of the possible features, but it may not have two instances of the same feature. Thus, for instance, a language may have a case system, or not have one, but it may not have two case systems. This conjecture is not usually stated as such, but it surfaces in the use of terms: where a language might be analysed as going against the conjecture, we sometimes find terms chosen to avoid the issue. For the area we are discussing, we find languages which arguably have two gender-like systems being described as having a gender system and a classifier system (at least in part, we suggest, to avoid the need to propose concurrent features). We treat this conjecture as a useful guiding principle. We would try to avoid proposing two features of the same type if we can offer an adequate analysis with just one. Thus Goddard (1982) showed how a single case feature provides a better analysis of systems previously analysed as showing split ergativity (implying two case features). The reanalysis of Kayardild as having not two TAM systems but one is another example (Round \& Corbett 2016). But we stress that we do not rule out concurrent feature systems in principle.

From that perspective, we take a critical view of analyses with concurrent features. We re-examined the evidence of Mian, and confirmed the analysis with concurrent gender/classifier systems. We call these concurrent, i.e., systems of the same type operating in the same language, since Mian helps confirm the view that there is no clear boundary to be drawn between gender and classifiers (see Corbett \& Fedden 2016). More generally, our approach to recognizing features, and hence establishing a basis for concurrent systems, relates directly to work in Canonical Typology (the criteria for canonical features and values are discussed in Corbett (2012: 156-163)). We have clarified and extended those proposals.

\subsection{For concurrent systems}

The issue of concurrent systems matters because it shows one more time that in linguistic argumentation it is important to be explicit. If we are to achieve an adequate typology in this area we need argued cases to depend on. Therefore it matters that descriptions, especially grammars, should consider the issue rather 
than simply assuming an answer. The issue also matters for psycholinguistics and the question of how speakers acquire and use features and concomitantly how they change over time.

We have noted an instance of a language with concurrent systems, namely Paumarí. Equally there are secure instances of single systems, such as Lamnso. Our canonical account of such systems in Section 3 provided for these two extremes, and for various less clear-cut possibilities. Mian is an instance of one such type, namely B3, having (as previously analysed) overlapping systems of grammatical meaning but different formal realizations. When we examined the degree to which the systems of grammatical meaning were orthogonal, the low orthogonality score (0.17) and the high total normalized discrepancy score (0.76) made us want to examine the system more closely. We did so using the tests devised by Round \& Corbett (2016) for another difficult case. Our conclusion is that the evidence indicates that Mian should indeed be recognized as having concurrent systems of gender/ classifiers. We take the view that it is no longer possible to draw a dividing line between gender and classifiers; we can therefore analyse Mian as a language with concurrent systems of the same type. Thus our canonical approach has led us to a better account of the Mian data (including the remarkable intersection with number), and to a fuller picture of possible concurrent systems (refining the typology presented in Section 3). We suspect that there is still more to be learned from Mian, for the analysis of concurrent systems.

Abbreviations: $1 / 2 / 3=1 \mathrm{st} / 2 \mathrm{nd} / 3 \mathrm{rd}$ person; $\mathrm{ACC}=$ accusative; $\mathrm{ADNOM}=$ adnominal element obligatory with the distal demonstrative in adnominal use; $\mathrm{AN}=$ animate; $\mathrm{ART}=$ article; $\mathrm{AUX}=$ auxiliary $; \mathrm{CVR}=$ covering classifier; $\mathrm{DECL}=$ declarative; $\mathrm{DEF}=$ definite; DEM = demonstrative; F = feminine; F_CL = F-classifier; HORT = hortative; IND = indicative; IPFV = imperfective; IRR = irrealis; $M=$ masculine; $M \_C L=M$-classifier; $\mathrm{MED}=$ medial verb; $\mathrm{OBJ}=$ object; $\mathrm{PFV}=$ perfective; $\mathrm{PL}=$ plural; $\mathrm{PST}=$ past; $\mathrm{R}=$ recipient; $\mathrm{REAL}=$ realis; $\mathrm{REDUP}=$ reduplicant; $\mathrm{RESD}=$ residue classifier; $\mathrm{RPST}=$ remote past; $\mathrm{SBJ}=$ subject; $\mathrm{SG}=$ singular.

Acknowledgements: This research was funded by the AHRC (UK) under grants $\mathrm{AH} / \mathrm{K003194/1} \mathrm{"Combining} \mathrm{Gender} \mathrm{and} \mathrm{Classifiers} \mathrm{in} \mathrm{Natural} \mathrm{Language”} \mathrm{and}$ AH/N006887/1 "Lexical Splits: A Novel Perspective on the Structure of Words". This support is gratefully acknowledged. For helpful discussion leading up to the article we thank Erich Round, Tom Güldemann, and Tim Feist. We are 
grateful to Matthew Baerman, Francesca Di Garbo, Tim Feist, Tom Güldemann, Tania Paciaroni, Matthias Passer, Maïa Ponsonnet, Erich Round, Hedvig Skirgård, and Anna Thornton for reading and commenting on an earlier version of this article; and to Penny Everson and Lisa Mack for their help in preparing the manuscript. We thank our Mian consultants, Kasening Milimap, Liden Milimap, and Asuneng Amit. All examples are elicited, except where the textual source is given in square brackets after the example. Corbett and Fedden are joint authors of most of this article (the order of names is not significant); Raphael Finkel has had a major input, primarily in Section 6, where the question of orthogonality is explored in depth.

\section{Appendix A: Verbs that require a classifier}

The verbs that require a classifier - with a few exceptions - refer to various forms of entity handling or movement, for example 'give', 'take', 'put', 'lift', 'turn' 'throw', 'bury', and 'fall'. The list here is exhaustive.

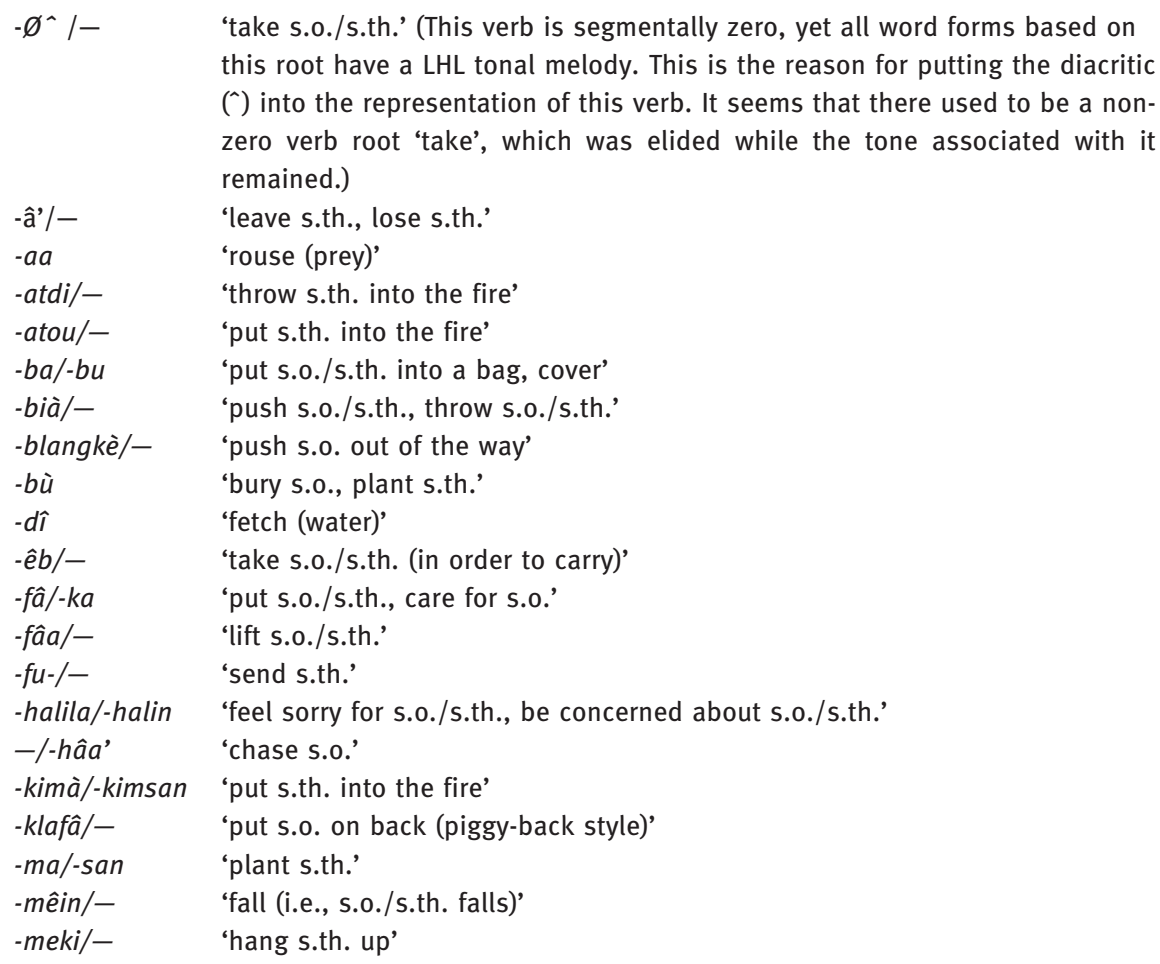




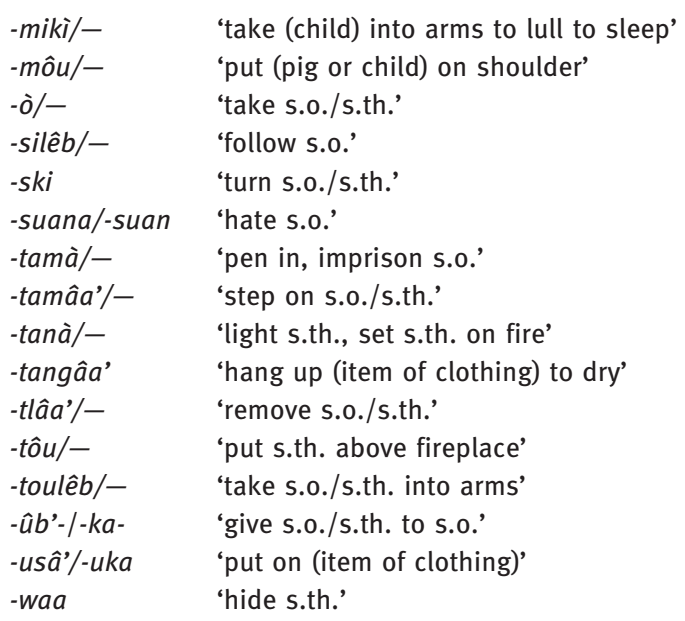

In two cases, the classifier is frozen in the singular form of the RESIDUECLASSIFIER $o b$-, namely as ob-tanà [fire 3SG.RESD.OBJ-light] 'light, set on fire' and aai ob-dî [water 3SG.RESD.OBJ-fetch] 'fetch water'.

Some of the verbs that take classifiers are subject to animacy restrictions, e.g., -êb/- 'take s.o./s.th. (in order to carry)' and -halila/-halin 'be concerned about s.o./s.th.', where the referent can be animate, and -/-hâa' 'chase s.o.' or -suana/-suan 'hate s.o.', where the referent has to be animate. For some verbs the referent has to be inanimate, e.g., -ma/-san 'plant', -meki/- 'hang up', and -tangâa' 'hang up item of clothing to dry'.

\section{Appendix B: Comparison with Burmeso}

Burmeso is a language spoken in the Mamberamo River area of Western New Guinea, as described by Donohue (2001). Burmeso has arguably two different gender systems, one marked by agreement on the verb (on an absolutive basis) and another (with some different distinctions) marked on adjectives. The details can be found in Donohue (2001), where there is also a representative word list, from which Corbett (2012: 176-180) extracted the system matrix given in Table B-1. In this table, genders I to VI are marked on the verb, and those labelled M, F, and so on are marked on the adjective. We stress, again, though that the semantics of the systems are partially distinct. 
Table B-1: Gender systems in Burmeso.

\begin{tabular}{|c|c|c|c|c|c|c|}
\hline & M & $\mathbf{F}$ & $\mathbf{N}$ & M INAN & F INAN & N ANIM \\
\hline I & $\begin{array}{l}44 \text { plus } \\
\text { all male } \\
\text { kin terms }\end{array}$ & $\begin{array}{l}5(4 \\
\text { birds })\end{array}$ & & 1 ('neck') & & $\begin{array}{l}2 \text { ('sea', } \\
\text { 'wound') }\end{array}$ \\
\hline II & & $\begin{array}{l}7 \text { plus all } \\
\text { female } \\
\text { kin terms }\end{array}$ & 4 & & $\begin{array}{l}1 \text { ('small } \\
\text { goanna') }\end{array}$ & $\begin{array}{l}2 \text { ('sago rinser } \\
\text { (lower)', } \\
\text { 'string. } \\
\text { shapes') }\end{array}$ \\
\hline III & 3 & & $\begin{array}{l}28 \text {, mainly } \\
\text { inanimate }\end{array}$ & $\begin{array}{l}10, \\
\text { inanimate }\end{array}$ & $\begin{array}{l}1 \\
\text { ('goanna') }\end{array}$ & \\
\hline IV & $\begin{array}{l}9, \\
\text { inanimate }\end{array}$ & & & & & \\
\hline V & & & & $\begin{array}{l}2 \text { ('banana', } \\
\text { 'sago tree') }\end{array}$ & & \\
\hline VI & & & 1 ('arrow') & 1 ('coconut') & & \\
\hline
\end{tabular}

For our simple measure of orthogonality of the two candidate systems, we calculate as follows:

$$
\frac{(\text { cells filled }- \text { minimum cells filled })}{(\text { possible cells }- \text { minimum cells filled })}=\frac{(16-6)}{(36-6)}=\frac{10}{30}=.33
$$

This score is higher than that for Mian. To apply normalized total discrepancy we include just the counts of actual nouns (121 in all), and leave out additional indicators for which we have no numbers (e.g., 'all female kin terms'). Then the normalized discrepancy is .58, again closer to the canonical standard for concurrent systems than is Mian (score .76). Recall that on this measure lower scores indicate closeness to concurrent systems. Both the orthogonality measure and the normalized total discrepancy measure agree that Burmeso displays a greater proximity to a canonical concurrent-system arrangement than Mian. 


\section{References}

Aikhenvald, Alexandra Y. 2000. Classifiers: A typology of noun classification devices. Oxford: Oxford University Press.

Aikhenvald, Alexandra Y. 2010. Gender, noun class and language obsolescence: The case of Paumarí. In Eithne B. Carlin \& Simon van de Kerke (eds.), Linguistics and archaeology in the Americas: The historization of language and society, 235-252. Leiden: Brill.

Audring, Jenny. Forthcoming. Canonical, complex, complicated? In Francesca Di Garbo \& Bernhard Wälchli (eds.), Grammatical gender and linguistic complexity. Berlin: Language Science Press.

Baerman, Matthew, Dunstan Brown \& Greville G. Corbett. 2005. The syntax-morphology interface: A study of syncretism. Cambridge: Cambridge University Press.

Bakker, Peter. 1997. A language of our own: The genesis of Michif, the mixed Cree-French language of the Canadian Métis. New York: Oxford University Press.

Bakker, Peter \& Robert A. Papen. 1997. Michif: A mixed language based on Cree and French. In Sarah G. Thomason (ed.), Contact languages: A wider perspective, 295-363. Amsterdam: Benjamins.

Bond, Oliver. Forthcoming. Canonical typology. In Jenny Audring \& Francesca Masini (eds.), The Oxford handbook of morphological theory. Oxford: Oxford University Press.

Boush, Al. 1975. Tifal grammar essentials. Manuscript, Summer Institute of Linguistics, Ukarumpa. http://www-01.sil.org/pacific/png/pubs/928474531256/Tifal_gram_essent.pdf

Brown, Dunstan \& Marina Chumakina. 2013. What there might be and what there is: An introduction to Canonical Typology. In Brown et al. (eds.) 2013, 1-19.

Brown, Dunstan, Marina Chumakina \& Greville G. Corbett (eds.). 2013. Canonical morphology and syntax. Oxford: Oxford University Press.

Chapman, Shirley \& Desmond C. Derbyshire. 1991. Paumarí. In Desmond C. Derbyshire \& Geoffrey K. Pullum (eds.), Handbook of Amazonian languages, Vol. 3, 161-352. Berlin: Mouton de Gruyter.

Corbett, Greville G. 1991. Gender. Cambridge: Cambridge University Press.

Corbett, Greville G. 2000. Number. Cambridge: Cambridge University Press.

Corbett, Greville G. 2006. Agreement. Cambridge: Cambridge University Press.

Corbett, Greville G. 2012. Features. Cambridge: Cambridge University Press.

Corbett, Greville G. 2013. Canonical morphosyntactic features. In Brown et al. (eds.) 2013, 48-65.

Corbett, Greville G. \& Sebastian Fedden. 2016. Canonical gender. Journal of Linguistics 52. 495-531.

Corbett, Greville G. \& Richard J. Hayward. 1987. Gender and number in Bayso. Lingua 73. 1-28.

Donohue, Mark. 1997. Tone systems in New Guinea. Linguistic Typology 1. 347-386.

Donohue, Mark. 2001. Animacy, class and gender in Burmeso. In Andrew Pawley, Malcolm Ross \& Darrell Tryon (eds.), The boy from Bundaberg: Studies in Melanesian linguistics in honour of Tom Dutton (Pacific Linguistics 514), 97-115. Canberra: Australian National University.

Fedden, Sebastian. 2007. Women, houses, and plural objects? - Homophony in the Mian gender system. In Robyn Loughnane, Cara Penry Williams \& Jana Verhoeven (eds.), In between wor(l)ds: Transformation and translation (School of Languages and Linguistics 
Postgraduate Research Papers on Language and Literature 6), 183-198. Melbourne: University of Melbourne. http://hdl.handle.net/11343/34686

Fedden, Sebastian. 2010. Ditransitives in Mian. In Andrej Malchukov, Martin Haspelmath \& Bernard Comrie (eds.), Studies in ditransitive constructions: A comparative handbook, 456-485. Berlin: De Gruyter Mouton.

Fedden, Sebastian. 2011. A grammar of Mian. Berlin: De Gruyter Mouton.

Fedden, Sebastian \& Greville G. Corbett. 2017. Gender and classifiers in concurrent systems: Refining the typology of nominal classification. Glossa 2(1). Article 34. http://doi.org/10. $5334 /$ gjgl.177

Foley, William A. 2000. The languages of New Guinea. Annual Review of Anthropology 29. 357-404.

Gerner, Matthias \& Walter Bisang. 2008. Inflectional speaker-role classifiers in Weining Ahmao. Journal of Pragmatics 40. 719-732.

Gerner, Matthias \& Walter Bisang. 2009. Inflectional classifiers in Weining Ahmao: Mirror of the history of a people. Folia Linguistica Historica 30. 183-218.

Goddard, Cliff. 1982. Case systems and case marking in Australian languages: A new interpretation. Australian Journal of Linguistics 2. 167-196.

Grinevald, Colette. 2000. A morphosyntactic typology of classifiers. In Gunter Senft (ed.), Systems of nominal classification, 50-92. Cambridge: Cambridge University Press.

Grondona, Verónica María. 1998. A grammar of Mocoví. Pittsburgh, PA: University of Pittsburgh doctoral dissertation.

Healey, Alan. 1964. The Ok language family in New Guinea. Canberra: Australian National University doctoral dissertation.

Healey, Phyllis. 1965. Telefol noun phrases (Pacific Linguistics B-4). Canberra: Australian National University.

Keenan, Edward L. 1984. Semantic correlates of the ergative/absolutive distinction. Linguistics 22. 197-223.

Kilarski, Marcin. 2013. Nominal classification: A history of its study from the classical period to the present. Amsterdam: Benjamins.

McGarrity, Laura W. \& Robert Botne. 2001. Between agreement and case marking in Lamnso. In Robert Botne \& Rose Vondrasek (eds.), IUWPL 3: Explorations in African linguistics: From Lamnso' to Sesotho, 53-70. Bloomington, IN: IULC Publications.

Passer, Matthias Benjamin. 2016. (What) Do verbal classifiers classify? Lingua 174. 16-44.

Pawley, Andrew. 2005. The chequered career of the Trans New Guinea hypothesis: Recent research and its implications. In Pawley et al. (eds.) 2005, 67-108.

Pawley, Andrew, Robert Attenborough, Jack Golson \& Robin Hide (eds.). 2005. Papuan pasts: Cultural, linguistic and biological histories of Papuan-speaking peoples (Pacific Linguistics 572). Canberra: Australian National University.

Polinsky, Maria. 2003. Non-canonical agreement is canonical. Transactions of the Philological Society 101. 279-312.

Ross, Malcolm. 2005. Pronouns as a preliminary diagnostic for grouping Papuan languages. In Pawley et al. (eds.) 2005, 15-66.

Round, Erich R. \& Greville G. Corbett. 2016. The theory of feature systems: One feature versus two for Kayardild tense-aspect-mood. Morphology 27. 21-75.

Savà, Graziano. 2011. Endangered Bayso (Cushitic): Interesting typological and historical aspects. In Luca Busetto, Roberto Sottile, Livia Tonelli \& Mauro Tosco (eds.), He bitaney 
lagge: Studies on language and African linguistics in honour of Marcello Lamberti, 163-174. Milano: Qu.A.S.A.R.

Seifart, Frank. 2005. The structure and use of shape-based noun classes in Miraña (North West Amazon). Nijmegen: Radboud Universiteit Nijmegen doctoral dissertation. http://hdl.han dle.net/2066/26990.

Seifart, Frank. 2010. Nominal classification. Language and Linguistics Compass 4. 719-736.

Singer, Ruth. Forthcoming. Beyond the classifier/gender dichotomy: Ideas for an integrated approach to the typology of nominal classification with reference to the analysis of Mawng (Australia). To appear in Sebastian Fedden, Jenny Audring \& Greville G. Corbett (eds.), Noncanonical gender systems. Oxford: Oxford University Press.

Thornton, Anna M. 2009. Constraining gender assignment rules. Language Sciences 31. 14-32.

Unterbeck, Barbara. 2000. Verbal classification and number: A case study in Navajo (Athapaskan/Na-Dene). In Barbara Unterbeck, Matti Rissanen, Terttu Nevalainen \& Mirja Saari (eds.), Gender in grammar and cognition, 401-460. Berlin: Mouton de Gruyter.

Weber, Thomas. 1997. Bimin grammar essentials. Manuscript, Summer Institute of Linguistics, Ukarumpa. http://www-01.sil.org/pacific/png/pubs/928474543843/Bimin_Grammar_ Essentials.pdf

Wurm, Stephen A. 1982. Papuan languages of Oceania. Tübingen: Narr.

Zaliznjak, Andrej A. 1973. O ponimanii termina "padež" v lingvističeskix opisanijax. [Interpreting the term "case" in linguistic descriptions.] In Andrej A. Zaliznjak (ed.), Problemy grammatičeskogo modelirovanija, 53-87. Moskva: Nauka. Reprinted in Andrej A. Zaliznjak, Russkoe imennoe slovoizmenenie: $S$ priloženiem izbrannix rabot po sovremennomu russkomu jazyku i obščemu jazykoznaniju, 613-647. Moskva: Jazyki slavjanskoj kul'tury, 2002. 


\section{Editorial postscript}

Description is guided by theory and theory feeds on description: it's a virtuous rather than vicious circle, and little authenticity is to be expected on either side without concurrence of descriptive and explanatory efforts. It's obvious, but bears constant underlining. This is why the Georg von der Gabelentz Award of the Association for Linguistic Typology was established, honouring expert grammar-writing, enhanced through being au courant with current typology and apt to enrich the theorising about diversity and unity, thus following in the footsteps of the prize's eponym. Factually-grounded theoretically-minded typology is of course LT's bread and butter, but we welcome special opportunities to present research derivative of ALT-award work in our pages.

We confidently assert that Mian would not have come to star in debates about inflectional morphology without being ushered onto the scene by Sebastian Fedden's A grammar of Mian (Berlin: De Gruyter Mouton, 2011). This grammar was the winner of ALT's Georg von der Gabelentz Award for 2013, and the jury's citation explains their selection:

Sebastian Fedden's A grammar of Mian (Trans New Guinea) is a truly excellent grammar that goes beyond a synchronic description. Based on eleven months of fieldwork, it covers the full range of descriptive topics and contains a large number of illustrative examples. The motivations underlying the author's analyses are usually presented in a clear and thorough manner, and the discussion is always typologically informed. The author has come up with excellent and original solutions in the difficult area of how to analyze the complex tonal system. This grammar furthermore has a highly useful and substantial index and table of contents, a high level of clarity of prose, explanation and organization, a high quality and richness of texts and vocabulary. Finally, engaging in areal, genealogical and typological discussions, it goes beyond the standard expectations of reference grammars in general. We should count ourselves lucky for having such a grammar.

Inspired by Fedden's grammar, already aware of the analytic intricacies of what was being described under the headings of genders and noun classes, the preceding article, with Fedden as one of the authors, adds theoretical depth to the analysis.

$L T$ joins in congratulating the prize winner. 